This item was submitted to Loughborough's Research Repository by the author.

Items in Figshare are protected by copyright, with all rights reserved, unless otherwise indicated.

\title{
Development of novel synthetic muscle tissues for sports impact surrogates
}

PLEASE CITE THE PUBLISHED VERSION

http://dx.doi.org/10.1016/j.jmbbm.2014.08.011

PUBLISHER

(c) Elsevier Ltd

VERSION

AM (Accepted Manuscript)

\section{PUBLISHER STATEMENT}

This work is made available according to the conditions of the Creative Commons Attribution-NonCommercialNoDerivatives 4.0 International (CC BY-NC-ND 4.0) licence. Full details of this licence are available at: https://creativecommons.org/licenses/by-nc-nd/4.0/

\section{LICENCE}

CC BY-NC-ND 4.0

\section{REPOSITORY RECORD}

Payne, Tom, Sean Mitchell, Richard Bibb, and Mark Waters. 2014. "Development of Novel Synthetic Muscle Tissues for Sports Impact Surrogates". Loughborough University. https://hdl.handle.net/2134/16594. 


\title{
Title: Development of Novel Synthetic Muscle Tissues for Sports Impact Surrogates
}

\author{
Authors: \\ Thomas Payne, Sports Technology Institute, Loughborough University, UK \\ Dr. Séan Mitchell, Sports Technology Institute, Loughborough University, UK * \\ Dr. Richard Bibb, Loughborough Design School, Loughborough University, UK \\ Prof. Mark Waters, School of Dentistry, Cardiff University, UK \\ *Tel.: +44(0)1509 564804; Fax: +44(0)1509 564801; E-mail: s.r.mitchell@lboro.ac.uk
}

\begin{abstract}
Impact injuries are commonplace in sport and often lead to performance detriment and debilitation. Personal Protective Equipment (PPE) is prescribed as a mandatory requirement in most sports where these impacts are likely to occur, though the methods of governance and evaluation criteria often do not accurately represent sports specific injury scenarios. One of the key shortcomings of such safety test standards is the human surrogate to which the PPE is affixed; this typically embodies unrepresentative geometries, masses, stiffness and levels of constraint when compared to humans.
\end{abstract}

A key aspect of any human surrogate element is the simulant material used. Most previous sports specific surrogates tend to use off-the-shelf silicone blends to represent all the soft tissue structures within the human limb segment or organ; this approach potentially neglects important human response phenomena caused by the different tissue structures.

This study presents an investigation into the use of bespoke additive cure Polydimethysiloxane (PDMS) silicone blends to match the reported mechanical properties of human relaxed and contracted skeletal muscle tissues. The silicone simulants have been tested in uniaxial compression through a range of strain rates and fit with a range of constitutive hyperelastic models (Mooney Rivlin, Ogden and Neo Hookean) and a viscoelastic Prony series.

\section{Keywords}

Polydimethysiloxane, Silicone, Compression, Mechanical Testing, PPE, Simulant, Sports, Muscle

\section{Highlights}

- Bespoke PDMS silicones formulated to better match relaxed and contracted muscle.

- PDMS simulants tested in uniaxial compression through a range of strain rates.

- Constitutive material models have been evaluated and fitted to experimental data. 


\section{Introduction}

\subsection{Background}

In contact sports, personal protective equipment (PPE) is often a mandatory requirement to ensure the safety of the participant is maintained throughout play and to prevent injuries that would otherwise restrict the ability of players to perform at a maximal level. At a professional level these injuries can result in a financial burden to clubs and sponsors; at a recreational level these injuries can result in avoidable healthcare costs and a burden to society in terms of days absent from the workplace.

Sports PPE is governed by safety standards (e.g. BS:EN 13546:2002; BS:6183-3:2000; BS:EN 13061:2000) which prescribe the form and minimal acceptable levels of impact protection that the garment must embody (Fig. 1). The standards are predominantly concerned with risks associated with blunt trauma from compressive impacts and dictate the nature of the striker and surrogate bodies employed to simulate impact. These are typically high-mass, rigid anvil surrogates with unrepresentative target segment geometries rigidly constrained to a massive base. The nature of this surrogate and the likely contact interactions will generate impact phenomena unrepresentative of those experienced by the human body in sport. For example, the proportions of strain energy absorbed by the surrogate and PPE will differ significantly between a stiff and compliant surrogate.

Figure 1 - Schematic showing a typical sports safety standard protocol used to assess projectile impacts (BS:13546:2002 Field Hockey Goalkeeper Protective Clothing; BS:6183-3:2000 Cricket Leg Protectors)

Due to ethical restrictions, i.e. the risk of subject injury, human surrogates are critical in the development of new sports PPE during two phases of the development cycle. Firstly, research conducted by manufacturers to better understand the performance of current PPE requires surrogates with greater biofidelity to observe product interactions with soft tissues influencing performance failure but that are not replicated in standard tests. Performance prediction/analysis through computational simulation is a worthwhile adjunct, provided that the PPE and surrogate are adequately represented, but a combined empirical/analytical simulation approach is preferable to overcome the inaccuracies and limitations inherent to both methods.

Secondly, during the new product evaluation phase it is arguably unethical to rely on computational analysis alone before human-use trials are conducted. Superior human surrogates that enable manufacturers to evaluate physical prototype PPE performance, without the risk of human injury, are needed to test the effectiveness of 'what has been made' rather than relying on 'what was intended or predicted.' The PPE industry, including the sporting goods sector, recognises that physical human surrogates are essential in this second phase. 


\subsection{Aims and Objectives}

Given the shortcomings associated with rigid surrogates used in sports PPE testing standards and the potential inaccuracies introduced through such measures there is a clear need for improved surrogates. A more biofidelic human body surrogate can potentially provide a better representation of the sports impacts experienced and provide a more accurate prediction of the effectiveness of PPE and the likelihood of injuries. Improved surrogate technologies have potential further applications in military ballistic impacts, automotive vehicle and pedestrian impacts, and medical training dummies.

The materials used in a synthetic human surrogate significantly affect their behaviour. It is important to match the dynamic stiffness of the human tissue structures to provide a biofidelic impact response (Saraf et al., 2007). Silicone rubbers have been previously used as a soft tissue simulant (e.g. Hrysomallis, 2009) due to their durability, consistency of response and comparable material density (approximately $1000 \mathrm{~kg} \cdot \mathrm{m}^{-3}$ ). A previous study, conducted by Payne et al. (2014) illustrated the benefits of a bespoke relaxed muscle tissue simulant when compared to Dow Corning Silastic 3481 single material simulant. The study showed the simulant produced a more biofidelic response under sports specific impact conditions in a simple puck geometry when using quasi-static material data to populate the material models.

Although previous sports impact surrogates have employed a single soft tissue material to represent all of the human structures (excepting bone) in a body segment, treating them as a homogenous block, it is believed that this approach fails to reproduce important interactions between different tissue structures such as variable stiffness, relative movement between structures, pressure distribution and deformation of tissues distant from the impact site. It is hypothesised that a structured multi-material soft tissue surrogate will provide a more biofidelic representation of human tissue response than single material constructions. The human body segments pertinent for this multi-layered soft tissue design are large fleshy areas surrounding a bone such as the thigh, upper arm and lower leg regions.

The dominant soft tissue in these fleshy regions is muscle. A further criticism of previous soft tissue surrogate materials is that they fail to reproduce the anisotropic behaviour of real muscle. There is a growing body of literature concerned with quantifying this aspect of muscle tissue behaviour (\$2.1) but achieving consensus and a complete description of human muscle behaviour in vivo loaded beyond quasi-static strain rates, that would enable the development of suitable anisotropic surrogate materials, is arguably some years away. In the meantime the sports and other PPE industries could benefit from improved physical surrogates based on better isotropic material combinations. Success in producing these intermediate surrogates arguably paves the way to the surrogates of the future containing synthetic anisotropic muscle tissue, particularly if these anisotropic materials are based on modified isotropic counterparts.

In this study, the development of improved relaxed and contracted muscle tissue simulants are presented for use in a superior multi-tissue human surrogate limb segment subject to blunt trauma from compressive impact. Although the ultimate goal of such simulants is to match all 
of the non-linear, anisotropic, viscoelastic material behaviour exhibited by organic muscle tissue a multi-layered surrogate based on isotropic materials represents a significant advancement in biofidelity from previous surrogate designs.

To this end a detailed description of the fabrication of additive cure silicones has been documented for both relaxed and contracted muscle tissue simulants. The fabrication of such simulants has been explored and the mechanical properties of the materials in uniaxial compression investigated through a range of representative strain rates. A range of commonly used constitutive models (Neo Hooke, Mooney-Rivlin and Ogden) have been fit to experimental data to describe their hyperelastic material behaviour. A Prony series expansion was also generated to describe their viscoelastic behaviour.

\section{Surrogate Materials Development}

\subsection{Structure and Composition of Organic Muscle Tissue}

Skeletal muscle constitutes the bulk of soft tissue in the human limb segments, accounting for 40-50\% of body mass (Wang et al., 1997; Salem et al., 2006), and as such is important to represent effectively. The microstructure of skeletal muscle tissues are characterised by a hierarchy of densely packed muscle fibres arranged in fascicles surrounded by connective tissues. Muscle tissue is heterogeneous and exhibits anisotropy, viscoelasticity, and strain rate dependencies.

It is very challenging to practically obtain in vivo muscle human data from mechanical tests and as such most studies are conducted ex vivo. There is also a paucity of good quality research in human tissue properties due to difficulties in obtaining post-mortem human subjects and the degradation in properties associated with the conditions the body is kept post-mortem prior to testing (Van Ee et al., 2000) and storage conditions (Menz, 1971; Lee \& Pelker, 1985; Clavert et al., 2001). Consequently, very few studies presented are of human tissues (Chawla et al., 2009; Balaraman et al., 2012). Much more of the muscle characterisation research published being obtained from testing on more accessible organic animal specimens such as bovine (McElhaney, 1966; Van Sligtenhorst et al., 2006) or porcine sources (Song et al., 2007; Van Loocke et al., 2006, 2008, 2009). It is suggested that these tissues exhibit anatomically and biologically similar structures to humans (Douglas, 1972; Snedeker et al., 2005). Although, Balaraman et al. (2012) reported that human muscle tissues studied were stiffer than both bovine and porcine equivalents.

Many other factors have been reported to affect the mechanical properties of characterised tissues:

- Age of the specimen: Song et al. (2007) noted a difference in mechanical response compared with the study conducted by Van Loocke et al. (2006) and partly attributed differences to the age of the specimens ( 3 and 5 month old animals respectively).

- Location of the specimen: Balaraman et al. (2012) observed significantly greater stiffness in tests conducted on in vitro human gastrocnemius muscles compared to soleus muscles when tested at comparable strain rates. 
- Directionality of testing: Several studies have acknowledged that porcine tissues behave stiffer when tested perpendicular to the direction of the muscle fibres (Van Loocke et al., 2006; Böl et al., 2012; Song et al., 2007).

- Time post-mortem prior to testing: Van Sligtenhorst et al. (2006) showed that there was a significant difference in the mechanical properties of specimens 1.5 and 3.5 hours post mortem when compared to specimens 5,6,7,9 and 27 hours post-mortem; this was largely supported by Van Loocke et al. (2006) who suggested that dehydration of tissues may lead to an increased stiffness.

- Shape of specimen: Inaccuracies may be introduced due to the specimen shape; it was reported that it was almost impossible to cut perfect shapes due to the high mobility of fresh muscle tissues (Böl et al., 2012; Van Loocke et al., 2006).

Many characterisation studies have been conducted investigating the mechanical properties of muscle tissues. Most tests are conducted in uniaxial compression and have been performed under quasi-static loading conditions (Yamada, 1970; Fung 1993), which are unrepresentative of the dynamic loading experienced from sports impacts. McElhaney (1966) conducted a seminal study characterising in vitro bovine tissues around the femur in uniaxial compression using both a Tinius-Olsen electromatic test machine and an air operated test machine for tests at low and high strain rates respectively. In recent years, authors have typically investigated the high strain rate response of soft tissues using a polymeric Split Hopkinson Pressure Bar (SHPB), capable of testing in the order of $10^{3} \mathrm{~s}^{-1}$ (Van Sligtenhorst et al., 2006; Song et al., 2007; Chawla et al., 2009; Balaraman et al., 2012). There is, however, a paucity of information conducted under intermediate strain rate conditions in a similar range to those expected in sports impact scenarios (approximately $50-500 \mathrm{~s}^{-1}$ ), based on a maximal velocity projectile impact from a cricket ball of $34.6 \mathrm{~ms}^{-1}$ (Penrose et al., 1976).

Engineering stress-strain data from a representative subset of studies are presented in Figure 2.

Figure 2 - Compressive engineering stress-strain plot showing data from previous organic tissue characterisation studies

The muscle property data, however, lacks tonicity that would be present in live humans; a very different response may occur when an athlete's limb segment is contracting, braced or tensed reflexively in anticipation of an impact. Although, it is widely suggested that muscles exhibit a greater stiffness when contracted (Hoffer \& Andreassen, 1981), there is no consensus quantifying the effect that muscle tonicity introduces. Many different studies have investigated the effect of contraction using a variety of techniques such as ultrasound and motion capture (Blackburn et al., 2009), magnetic resonance elastography (Bensamoun et al., 2006), vibro-ultrasound (Wang et al., 2012) and manual indentation and ultrasound (Zheng et al., 1999); the effects measured varied. Crisco et al., (1996) also observed a 44\% reduction in the delay between peak force and peak displacement between contracted and relaxed muscles when testing Wistar rats in vivo; this is an indication of reduced viscoelasticity in contracted muscles. Given no definite characterisation of this effect, a direct measurement by Zheng et 
al. (1999) was used to provide an approximation of the potential stiffness of a contracted skeletal muscle. The study used a manual ultrasound indentation system on the human forearm and lower limb soft tissues and recorded a mean increase in effective Young's modulus of 4.2 times when gripping a pen. Without further data to better inform this study, a uniform scaling factor of $4.2 \times$ the relaxed muscle stress-strain data was employed.

Given the large degree of variation between characterisation studies based on the specimen type and nature of mechanical loading (Fig. 2), it is clear that there is no consensus on the definitive structural response. Consequently, it is to be noted that this study aims to provide a close approximation of a representative target dataset, demonstrating the possibility of matching the properties of any particular set of organic tissue data (partly in anticipation of better definition of human tissue response in the future). The mechanical properties of the organic muscle tissue from uniaxial compression tests in the cross-fibre direction have been selected as target properties to mimic with silicone simulants. The materials have been characterised in compression to match the mechanical properties of muscle in the cross-fibre direction most pertinent to blunt force trauma in the aforementioned body regions of interest. Approximating the behaviour of an anisotropic organic material with a tailored isotropic one should yield a useful result when the anticipated loading of the simulant corresponds with the characterisation conditions for the organic tissue.

The organic tissue responses reported by McElhaney (1966) and Song et al. (2007) taken in the cross-fibre direction are nearly coincident in their overlapping strain ranges at both quasistatic and intermediate strain rate $\left(100-540 \mathrm{~s}^{-1}\right)$ ranges. Consequently, the stress-strain data were combined to a wider strain range (appropriate to blunt trauma from compressive impacts in sport). The scaled responses of contracted muscle tissue are also presented in Figure 3.

Figure 3 - Engineering stress-strain graphs showing organic tissue properties from relaxed (McElhaney, 1966; Song et al., 2007) and contracted (Zheng et al., 1999) muscle tissue in (a) linear and (b) log-linear plots

The success of the developed soft tissue simulants have been considered in relation to the following questions:

- Given current in vivo and ex vivo data, do the developed PDMS simulants exhibit a more biofidelic response than previously used single material simulants?

- In the future, given superior in vivo material properties, is there scope to use the same approach to produce to produce an improved PDMS formulation?

- Do the PDMS simulants perfectly match the organic tissue characteristics?

\subsection{Formulations}

Two-part (A and B) additive cure vinyl blocked Polydimethysiloxane (PDMS) silicones (Technovent Ltd., Bridgend, UK) were formulated through an iterative development process altering polymer and cross-linker constituent concentrations. It is possible to use, in different proportions, polymers of different chain lengths and so molecular weights. These cross-link within the silicone rubber by reacting at the end vinyl groups to form a cross-link network. 
Optimal cross-linking of longer polymer chains produces a more flexible elastomer; conversely, the use of a greater proportion of cross-linked shorter polymer chains produces a more inelastic/brittle polymer. In addition silica fillers are used to stabilise and reinforce the cross-linked matrix, adding strength but also stiffness to the resulting PDMS silicone.

In this study the part A component consisted of three different chain length polymers with vinyl termination $\left(\mathrm{CH}=\mathrm{CH}_{2}\right)$ : V21 (molecular weight: 6000 Daltons), V31 (molecular weight: 28,000 Daltons) and V46 (molecular weight: 117,000 Daltons). The concentrations of these polymers were varied to gain desired material properties.

Each polymer had 20\% (by mass) surface treated (hexamethyldisilazane treated) silica filler concentration to stabilise and reinforce the cross-linked matrix and increase the strength of the polymers. A $10 \%$ (by mass) concentration heat-cure platinum catalyst (platinum cyclovinylmethylsiloxane complex) was also present in the Part A solution, which permitted significant working time, requiring the application of heat to burn off the masking compound.

The Part B component consisted of a MethylHydrosiloxane-Dimethylsiloxane Copolymer (H301), which was used to chemically bond the polymer chains via a hydrosilation addition reaction $_{z}$ This was mixed in a 1:9 solution (by mass) with an unfilled V21 polymer acting as carrying agent for the cross-linker. The Part A:B ratios in the solutions were varied to alter the cross-linker concentration and thus change the material properties. A greater concentration of cross linker increases the stiffness of resultant silicones (Gelest, 2014).

Figure 4 - Quasi-static compressive engineering stress-strain plot of silicones with different cross-linker concentrations in: (a) linear and (b) log-linear graphs

The chemical structure of the additive cure reaction is shown in Figure 5.

Figure 5 - Chemical structure of additive cure PDMS silicone reaction

\subsection{Fabrication Procedures}

The process by which the silicones were prepared may significantly affect the mechanical properties of the cured elastomer. Factors such as weighing inaccuracies, method of mixing, time left before curing and the temperature of cure can all alter the quality of the resulting silicones. The process employed in the silicone development is outlined in below:

1. Weighing of constituents ( $\pm 0.1 \mathrm{~g}$ accuracy)

2. Constituents poured and mixed manually for 2-3 minutes

3. Silicones vacuumed for 20-30 minutes until fully degassed.

4. Moulds coated in several layers of release wax and Polyvinyl Acetate (PVA) release agent.

5. Solutions poured into specimen moulds immediately after vacuuming.

6. Specimens heated at $60^{\circ} \mathrm{C}$ in an environmental chamber until cured (approx. 30 minutes). 
7. Cured specimens removed from moulds and cleaned from contaminate left by the release agents using a standard commercial cleaning solution.

The bespoke silicone blends developed for the muscle tissue simulants were formulated through an iterative process:

- A range of different 'Part A' formulations with V46:V31:V21 ratios from 85\%:10\%:5\% to 52\%:24\%:24\% were combined in a range of Part A:B ratios from 10:1 to 1:1

- Uniaxial compression testing under quasi-static loading rates was used to evaluate material samples against the target organic tissue dataset.

- Further incremental formulation adjustment was conducted on blends indicating a promising match.

The final formulations are presented in Table 1.

Table 1 - Part A and B silicone constituent concentrations (\% by mass)

\section{Mechanical Testing Procedures}

\subsection{Background}

To gain a comprehensive understanding of material behaviour both stress-strain data and viscoelastic material properties are required. It is also important to characterise the material at strain rates representative of those experienced by the surrogates in sports impact scenarios. Muscle tissues have been demonstrated to exhibit both large strain deformations in vivo and high strain rate dependencies when subject to impact stimuli (Van Loocke et al., 2006; Song et al., 2007). Given the nature of many sports impacts, high strain rate, high strain deformations are also likely and as such require material characterisation at comparable rates to ensure consistency of response and adequately populate associated parallel Finite Element (FE) models.

Silicone elastomers typically exhibit a high strain rate sensitivity, which is attributed to the timescale required for polymer chains to re-orientate during deformation. During deformation at low strain rates the polymers have significant time to reorient, whilst at high strain rates the deformation of polymer chains is restricted to bending and stretching of chemical bonds (Shergold et al., 2006). Many high strain rate characterisation procedures use an oscillatory dynamic test machine (e.g. Instron Electropuls), which can test materials at high strain rates but compromises the degree of mechanical strain (e.g. Arbogast et al., 1997; Van Loocke, 2009). These test machines also introduce ringing phenomena, inertial effects and inaccuracies from the elastic response of the machines influencing the stress-strain outputs.

Filled silicone elastomers are also widely reported to exhibit the Mullins effect (Mullins, 1969; Yan et al., 2012; Rey et al., 2013) and this has therefore been studied to examine the extent of their effect in the developed materials. The presence of such an effect has been used to understand the steady state material behaviour, where the loading curves become almost coincident following repeat loading cycles, and was subsequently used to populate material 
models. This information could also potentially inform the manner in which physical synthetic surrogates are handled prior to testing and whether preconditioning may be necessary to ensure consistency of response.

\subsection{General Procedure}

A series of unconfined uniaxial compressive tests were conducted using ASTM D395 cylindrical material specimens (29mmØ, $12.5 \mathrm{~mm}$ height). For each of the specimens, the ends were coated with a Vaseline lubricant to reduce plate-specimen friction and barrelling effects, which can account for up to a 50\% error in compressive stress (Wu et al., 2004). All tests were conducted at room temperature $\left(22^{\circ} \mathrm{C}\right)$, within the guidelines of $23 \pm 2^{\circ} \mathrm{C}$ stipulated by ASTM D1349 for rubber testing. Humidity was not controlled in the experiments.

\subsection{Low Strain Rate Tests}

Quasi-static strain rate tests $\left(0.4 s^{-1}\right)$ were conducted with an Instron 5569 screw driven universal test machine using a range of load cells between $100 \mathrm{~N}$ and $50 \mathrm{kN}$ sensitivity dependent on the specimen tested and a linear variable differential transformer (LVDT) to determine displacement with a sampling rate of $100 \mathrm{~Hz}$. Each specimen was placed directly between flat compressive platens and aligned to ensure planarity and parallelism; the load cell and LVDT were zeroed prior to testing. The software was programmed to perform a triangular cyclic compressive protocol to ensure a constant strain rate was maintained in loading and unloading cycles. The specimen was compressed incrementally through six loading/unloading cycles in 0.1 compressive strain intervals until failure (Fig. 6). This incremental procedure was adopted to investigate the presence of the Mullins effect in the material following previous guidelines and usage by Dorfmann \& Ogden (2004) and Diani et al. (2009).

Figure 6 - Programmed triangular loading profile for quasi-static uniaxial compressive tests

The Poisson's ratio was an important parameter to measure as only compressive loading tests were conducted; this ratio is the sole determinant of volumetric change in the material and therefore the behaviour in other mechanical loading directions. The deformations were measured using a high speed imaging camera aligned perpendicular to the specimen and captured at 2000 frames per second (fps).

\subsection{Intermediate Strain Rate Tests}

An Instron 9250 drop tower was used to test the material to both intermediate strain rates and high strains. The test machine is equipped with three piezoelectric load cells beneath the bottom compressive platen. A high speed, high resolution video camera was used to measure specimen displacement. The camera had a 256k greyscale image resolution of 1024x1024 pixels $(\approx 100 \mathrm{~mm} \times 100 \mathrm{~mm})$, shutter speed of $1 / 10000$ s and was operated at a frame rate of 4000fps to provide sufficient spatial and temporal resolution to accurately measure changes in strain. A 6.8kg mass with a flat compressive platen end effector was dropped from a series 
of heights $(0.01 \mathrm{~m}-0.5 \mathrm{~m})$ to induce high strain at a range of strain rates in the material. The strain rates reported are characterised by the initial maximum value recorded.

\subsection{Stress Relaxation Tests}

Uniaxial ramp-and-hold stress relaxation tests were performed on the Instron 5569 to understand the viscoelastic time-dependant properties of the material. The compressive strain levels induced in test specimens vary across standardised tests (ISO 3384-1:2011; ASTM D6147-97:2008). The strain chosen was the highest strain attained by all materials before failure (established previously) was selected to characterise the materials under the most representative conditions for compressive sports impacts. Each specimen was deformed to 0.5 strain at a rate of $0.4 \mathrm{~s}^{-1}$ and held under constant strain for a period of 300s. The 300s time period was used previously by Van Loocke et al. (2008) and was shown to be sufficient for the materials to achieve a steady relaxed state.

\subsection{Analysis Procedures}

Force-time and displacement-time data were obtained from the mechanical tests. The engineering strain ( $\varepsilon$ ) at each time interval was calculated with Equation (1) using displacement values and the original length measured prior to testing using a set of Vernier callipers $\left( \pm 1 \times 10^{-5} \mathrm{~m}\right)$. Engineering stress $(\sigma)$ was calculated (Equation 2$)$ using data from the load cell divided by an original cross-sectional area of $6.6 \times 10^{-4} \mathrm{~m}^{2}$.

$$
\varepsilon=\frac{\Delta l}{l_{0}}
$$

Where: $l_{0}=$ original length; $\Delta l=$ change in length.

$$
\sigma=\frac{F}{A_{0}}
$$

Where $F$ = applied load; $A_{0}=$ original cross-sectional area

There is currently no consensus as to the best method to quantify the extent of the Mullins effect (Diani et al., 2009). In this study, the maximal stress reductions from the loading curve of the first to last cycle at maximal strain were calculated.

The Poisson's ratio (v) was determined through post processing of the imaging output using video analysis software Image Pro Analyser (Media Cybernetics Inc.) to determine the relative ratio of transverse and axial strains (Eq. 3).

$$
v=-\left(\frac{\Delta \varepsilon_{\text {trans }}}{\Delta \varepsilon_{\text {axial }}}\right)
$$

Where: $d \varepsilon_{\text {trans }}=$ change in transverse strain; $d \varepsilon_{\text {axial }}=$ change in axial strain

The intermediate strain rate drop tests were post-processed using the load cell data and positional output from video analysis. The loading curves from each dataset were extracted 
and used to calculate compressive stress-strain parameters at each time increment. The data was then smoothed using polynomial fits to remove noise introduced from the load cell output (Fig. 7).

Figure 7 - Processing of intermediate strain rate drop tower data: (a) raw data; (b) smoothed stress-strain plot

\section{Results}

\subsection{Low Strain Rate Tests}

Engineering stress-strain results for both relaxed and contracted muscle simulant materials (Table 1) are shown in Figure 8a and 8b in comparison with the published organic tissue data (cf. Fig. 3). The graphs illustrate that both simulant materials show responses in the same stiffness range as organic tissues, however, the nature of the responses differ. The greatest divergence was present in the contracted muscle simulant at low strains with an error of up to $250 \%$. The silicone simulants typically initially exhibit a stiffer response up to approximately 0.4 strain at which point the organic tissues stiffen by a greater magnitude than the silicones.

The responses of the Silastic 3481 simulant were also compared to the target organic tissue datasets under quasi-static strain rates (Fig. 8c, 8d). The simulant provided a poor approximation of relaxed muscle simulant with errors at low strains of over $4000 \%$ but showed a more comparable fit to the contracted muscle tissue simulant. The Silastic simulant followed the same stress response as the PDMS silicones with a weaker strain hardening being exhibited at approximately 0.4 strain.

A direct comparison of the closeness of fit of the contracted PDMS silicone and Silastic 3481 simulants with the target organic tissue property dataset is shown in Figure 8e. The graph shows that both silicone simulants exhibit a far greater stress response compared to organic tissue data at low strains. This increased stiffness is most pronounced in the Silastic 3481 simulant which exhibited a significantly greater compressive stress response below 0.1 strain with up to $896 \%$ increased stiffness.

Figure 8 - Quasi-static stress-strain plots showing the divergences in compressive response between: (a) PDMS relaxed muscle simulant and organic tissue data; (b) PDMS contracted muscle simulant with organic tissue data; (c) Silastic 3481 with relaxed organic tissue data; (d) Silastic 3481 with contracted muscle organic tissue data; (e) Percentage errors plots showing divergence between silicone simulants and target organic contracted muscle data 


\section{Mullins Effect}

The percentage difference in compressive stresses between the first and last loading cycles at maximal strain were recorded and displayed in Figure 9.

Figure 9 - Engineering stress-strain plot showing stress softening effect in cyclic compressive protocol between the first and last cycles in: (a) PDMS relaxed muscle simulant and (b) PDMS contracted muscle simulant

The results show a far greater stress-softening effect was exhibited in the softer relaxed muscle simulant with a reduction in maximal stress of $12 \%$ compared to $0.7 \%$ recorded for contracted muscle under identical loading conditions. Both tissue simulants exhibit a significant hysteresis loss in the unloading cycles demonstrating their viscous behaviour.

\section{Poisson's Ratio}

The measured values of Poisson's ratio for relaxed and contracted muscle simulants were 0.493 and 0.480 respectively. Both simulants are shown to be virtually incompressible, in agreement with the literature concerned with elastomers (Ali et al., 2010; Mottahedi et al., 2011) and organic muscle tissue (Van Loocke et al., 2009; Böl et al., 2012). As reported elsewhere (Shergold et al., 2006), compressive testing of incompressible materials conveniently incorporates the biaxial tensile response of the specimen. 


\subsection{Intermediate Strain Rate Tests}

The response of the materials tested at a range of strain rates are shown in Figure 10. The results show an increase in the material stiffness of both simulants at increased strain rates.

Figure 10 - Intermediate strain rate engineering stress-strain curves for: (a) PDMS relaxed muscle simulant and (b) PDMS contracted muscle simulant

\subsection{Stress Relaxation Tests}

The magnitude of stress relaxation in the materials is shown in Figure 11 when held under a constant strain. The softer relaxed muscle specimen exhibited a far greater stress reduction.

Figure 11 Normalised stress-time plot showing stress relaxation in PDMS relaxed and contracted muscle simulants

\subsection{Dynamic Response Comparisons}

A previous study conducted by Payne et al. (2014) illustrated the benefits of the relaxed muscle tissue simulant when compared to Silastic 3481 when using quasi-static material properties. Further comparison is made in Figure 8 between the compressive stress-strain response of organic tissues (at quasi-static and intermediate strain rates) and Silastic 3481. Figure 8 also shows the stress-strain response of the PDMS relaxed and contracted muscle simulants (at similar strain rates). The banded regions show the response corridors for the PDMS simulants through the given range of strain rates.

Figure 12 - Log-linear engineering stress-strain plots showing a comparison between Silastic 3481, PDMS silicones and organic tissue properties for: (a) PDMS relaxed muscle simulant and (b) PDMS contracted muscle simulant

Figure 12 clearly shows that Silastic 3481 is much stiffer than organic tissues at both quasistatic and intermediate strain rates. The PDMS simulants provide a much closer representation of the organic tissue behaviour at low strain rates (especially the relaxed muscle simulant). At increased strain rates the PDMS simulants exhibit a far better representation of target organic tissue behaviour than Silastic 3481 but are unfortuantely less than ideal.

\section{Constitutive Modelling}

Silicone elastomers exhibit both elastic and viscous resistance to deformation as the materials retain the recoverable strain energy partially but dissipate energy if the deformation is maintained. Consequently, combinations of hyperelastic and viscoelastic models are needed to represent the non-linear and time-dependant behaviours of elastomeric materials. 


\subsection{Hyperelasticity}

The simulant materials all exhibit significant strain hardening effects and as such require hyperelastic models to describe their stress-strain behaviour. First order phenomenological models were evaluated which consider changes in stiffness based on the strain energy density $(W)$ of the material. The Ogden, Mooney-Rivlin and Neo Hookean have been widely used in literature to describe incompressible, hyperelastic materials (Marckmann \& Verron, 2006; Ali et al., 2010) and were evaluated for each material. The Ogden model (Ogden, 1972) is a commonly used hyperelastic model to describe the material behaviour of soft solids that are both isotropic and incompressible. The model proposes the strain energy function (W) is based on the principal stretches $\left(\lambda_{1}, \lambda_{2}, \lambda_{3}\right)$, with $\mu$ describing the shear behaviour and $\alpha$ describing the strain hardening (Equation 3). The Mooney-Rivlin model (Rivlin, 1948) is another commonly used material model to describe rubber-like behaviour due to its simplicity and ability to model moderate deformations and high strain hardening (Shergold et al., 2006; Meunier et al., 2008). It is a first order polynomial model represented by Equation (4) where $C_{10}$ is a material parameter and $C_{00}=0$. The Neo-Hookean model (Treloar, 1943) is a first order reduced polynomial. It is the simplest hyperelastic constitutive equation for describing rubber behaviour with only one material parameter $C_{10}$, and is often used when material data is insufficient (Marckmann \& Verron, 2006).

$$
\text { Ogden: } \quad W=\frac{2 \mu}{\alpha^{2}}\left(\bar{\lambda}_{1}^{\alpha_{\mathrm{i}}}+\bar{\lambda}_{2}^{\alpha_{\mathrm{i}}}+\bar{\lambda}_{3}^{\alpha_{\mathrm{i}}}-3\right)
$$

Where: $\lambda_{\mathrm{i}}=$ principal stretch ratios; $\mu, \alpha=$ material constants

$$
\text { Mooney-Rivlin: } \quad W=\sum_{i, j=0}^{N} C_{i j}\left(\bar{I}_{1}-3\right)^{i}\left(\bar{I}_{2}-3\right)^{j}
$$

Where: $\bar{I}_{1}, \bar{I}_{2}=$ stress invariants; $C_{i j}=$ material constants;

Neo-Hooke:

$$
W=C_{10}\left(\bar{I}_{1}-3\right)+\left(\bar{I}_{2}-3\right)
$$

Typically, FE solvers determine material parameters automatically by fitting a strain energy function to input uniaxial test data based on a non-linear least squares optimisation. A commercial FE solver, Abaqus Explicit (Version 6.13) was used to perform this analysis; the quality of the fits are shown in Figure 13 with generated material coefficients presented in Tables 2-4 alongside RMS errors showing the degree of divergence of each dataset from the experimental data.

Figure 13 - Hyperelastic model fits for: (a) PDMS relaxed muscle simulant and (b) PDMS contracted muscle simulant at a range of intermediate strain rates

The Mooney-Rivlin model typically provided a good fit $(<0.229 \mathrm{MPa}$ RMS error) for both simulants through the range of strain rates reported. The model, however typically underestimated the magnitude of strain hardening at high strains (e.g. relaxed muscle, $112 \mathrm{~s}^{-1}$ ). The Ogden model also generally provided a good fit $(<0.730 \mathrm{MPa}$ RMS error) through the 
range of strain rates tested but typically under predicted the compressive stresses under low strain, low strain rate conditions and over predicted the strain hardening present at higher strains ( $>0.5$ strain). The Neo Hooke model provided the worst performance of the three models and was unable to capture much of the non-linearity of the silicone behaviour, particularly in the stiffer contracted muscle simulant (e.g. contracted muscle, $50 \mathrm{~s}^{-1}$ and $\left.194 \mathrm{~s}^{-1}\right)$.

Table 2 - Mooney-Rivlin model coefficients for PDMS simulants

Table 3 - Ogden model coefficients for PDMS Simulants

Table 4 - Neo Hooke model coefficients for PDMS simulants

\subsection{Viscoelastic Models}

A generalised Maxwell model known as the Prony series (Tschoegl, 1989) was used to model the viscoelastic properties of the simulants. The Prony series models a series of Maxwell models in parallel and considers the relaxation of the materials through a series of time intervals. The force-time data from the stress relaxation tests were manipulated to determine the compressive stresses at each time interval. The uniaxial stresses were then normalised from the point of maximal stress to determine the shear modulus parameter, $g(t)$ (Equation 7). The materials are assumed to be incompressible and as such the bulk modulus parameter, $k(t)$ is considered to equal zero.

$$
\begin{gathered}
g(t)=\frac{\sigma(t)}{\sigma_{0}}, \quad \sigma_{0}=\sigma(0) \\
g(t)=1-\sum_{i=1}^{N} g_{i}\left(1-e^{-t / \tau_{i}}\right)
\end{gathered}
$$

The normalised shear modulus values were then used to generate time-dependent Prony series parameters using equation (9) in the automated feature of the FE solver fitting a curve to the relaxation data. The quality of the curve fits are shown in Figure 14 and the Prony series coefficients describing the viscoelastic behaviour of both simulants are shown in Table 5.

Figure 14 - Prony series model fits for: (a) PDMS relaxed muscle simulant and (b) PDMS contracted muscle simulants

Table 5 - Prony series coefficients for PDMS simulants

\section{Discussion}

\subsection{Organic Muscle Tissue Data}

Previous studies investigating the mechanical behaviour of muscle tissues have reported a wide range of responses when tested in compression. This is due to many factors relating to 
the specimen type and loading conditions utilised. Consequently, to provide an estimation of the general response of such tissues, representative data from studies by McElhaney (1966) and Song et al. (2007) were extracted and combined (Fig. 2). Response data characterised from studies conducted in the cross-fibre direction was utilised as an initial simplification of the anisotropic behaviour exhibited by muscle tissues (Van Loocke et al., 2006; Song et al., 2007; Böl et al., 2012).

A fundamental issue with the organic tissue data, however, is that it has been gathered postmortem and lacks tonicity. This is always present to some degree in humans due to neurological effects. Much current research has also been conducted at higher strain rates relevant to automotive or ballistic impacts, there currently a paucity of data at intermediate strain rates pertinent to sports impacts. This causes issues in extrapolating outputs to apply to these data ranges. Given no standardised measure for characterising organic tissues (in particular at high strain rates) much of the differences reported could be attributed to variability in the test methods. Studies typically use a SHPB to perform high rate materials characterisation. When experiments are conducted with high stiffness pressure bars errors can be introduced through inertial effects in low-impedance materials, which can often be at the same order of magnitude as mechanical properties making it difficult to determine intrinsic material behaviour (Song et al., 2007). More recent characterisation studies, however, have managed to overcome such issues. For example, a study by Trexler et al. (2011) developed practices for use of a modified SHPB with low impedance soft biomaterials using pulse shaping techniques and thin specimen sizes.

The target muscle tissue dataset was obtained from previous studies through a range of unmatched strain rates and loading conditions. A greater confidence in the mechanical behaviour could be obtained through internal testing of organic tissues at strains and strain ranges pertinent to sports impacts. This could potentially provide an enhanced target dataset from which to base new formulation of PDMS silicones.

The mechanical properties of contracted muscle tissue remain unknown and almost certainly vary with the levels of muscle contraction. Some previous research has concluded that contracted muscle is less susceptible to injuries than relaxed muscle (Crisco et al., 1996; Tsui $\&$ Pain, 2008) but this is not necessarily so. Given further research to better quantify the behaviour of contracted muscle new simulants could be formulated with the methods presented.

\subsection{Silicone Behaviour}

The developed PDMS silicone simulants each exhibited mechanical hysteresis, stress softening effect and strain rate dependency. Through the range of strain rates tested, the silicones exhibit a significant strain rate dependency whereby at higher strain rates the silicones experience a more pronounced strain hardening effect; this was more apparent in the stiffer contracted muscle simulant. This behaviour is consistent with results from literature (Gray III et al., 1997; Lee et al., 2003; Kakavas, 1996; Jones, 1960). Gray III et al. (1997) conducted uniaxial compressive tests on silicone rubbers and noted that the Young's modulus 
increased by a factor of 8 when strain rate was increased from $10^{-3}$ to $3 \times 10^{3} \mathrm{~s}^{-1}$, whilst little change was observed between strain rates $10^{-3}-10^{-1} \mathrm{~s}^{-1}$.

The cyclic compressive tests also showed that the simulants both experienced significant mechanical hysteresis losses, which were more prominent at higher strains. This is indicative of increased viscous behaviour at increased strain rates. The Mullins effect is also a pertinent phenomenon that changes the way in which elastomers behave after multiple deformations. The PDMS silicones each exhibited a Mullins effect, though this was far more pronounced in the softer muscle relaxed simulant. The coincident behaviour of the silicones after multiple deformations indicates that it may be necessary to precondition the specimens to ensure consistency of response. The presence of this effect was consistent with other studies, which have observed a Mullins effect in filled silicones (Yan et al., 2012; Rey et al., 2013).

The mechanical response phenomena experienced are in contrast to results from a study by Meunier et al. (2008), where little hysteresis, stress-softening and strain rate dependency were observed. This could be attributed to the lack of filler content in the silicones, which has been suggested to be a strain amplifier (Rault et al., 2006; Podnos et al., 2006; Mullins \& Tobin, 1965). The presence of filler particles in the silicone can significantly restrict the mobility of polymer chains and increase the degree of non-linearity exhibited (Cosgrove et al. 1997; Cassagnau \& Mélis, 2003). It is also suggested that less filled rubber exhibits purely entropic behaviour with no mechanical dissipation, whilst filled rubber exhibits both viscous and entropic behaviour, increasing temperature sensitivity (Martinez, 2013).The effect of temperature on the behaviour of the silicones, although controlled was not examined explicitly in this study and has potential effects on the mechanical response. Rey et al. (2013) noted that filled silicones exhibited an increase in stiffness at increasing temperatures which shows that the effects of entopic changes are much greater than viscous changes. A greater stress softening effect was also experienced in filled rubbers at lower temperatures below $60^{\circ} \mathrm{C}$. Further manipulation of the silicone formulations may consider the concentration and type of filler present in the polymer to alter the mechanical properties of the cured silicone and create improved parallels with the target organic data.

The variability between equivalent silicone blends was not presented in this study but the quality of blend is believed to affect the resultant stiffness of the material. The PDMS silicones are largely dependent on the consistency of mix, temperature and time of cure all relating to the number of cross-links produced. The values presented are intended to be an indication rather than absolute values for that particular formulation. Further research is required to establish batch sensitivity to minor variations in production variables for different quantities of simulant.

\subsection{Constitutive Modelling}

Three simple hyperelastic models were evaluated as representative subsets of commonly used material models. The Ogden and Mooney-Rivlin models provided the closest material fits through both simulants and the range of strain rates conducted. The quality of the constitutive model fits are generally in contrast with the findings from Meunier et al. (2008) and Shergold 
et al. (2006), who observed a weak Mooney-Rivlin fit, though the decreased strain hardening effect was noted when compared to the Ogden model. However, the variability present between hyperelastic fits and the difference of error in each does reiterate the need for caution when interpreting the results from FE models.

The constitutive models could potentially be improved for the simulant materials. Complex hyperelastic models such as the Bergström-Boyce model (Bergström \& Boyce, 1998), which model both hysteresis behaviour and strain rate dependency, could provide an improved singular description of the materials. Similarly, incorporating the viscoelastic material properties under higher strain rates could be beneficial. Van Loocke et al. (2008) showed the viscoelastic component of muscle tissue increased at higher compression rates. A better understanding of the simulant behaviour under these conditions would be useful and could potentially provide an improved description of the viscoelastic properties.

\subsection{PDMS Comparison with Organic Tissue}

\subsubsection{Are the PDMS formulations better than surrogate materials?}

The success criteria of the developed silicone simulants were detailed previously (§. 1.3) and have been outlined again below.

- Is there scope with current in vitro data to develop materials that exhibit a more biofidelic response than previously used single material simulants?

- If better in vivo material properties become known, is there scope to develop silicones to match the new data?

- Is it possible to develop a silicone simulant that perfectly matches the organic tissue properties?

Using existing in vitro material data from literature sources the quality of the PDMS simulant fits were evaluated. Under quasi-static loading conditions, the relaxed muscle tissue simulant exhibited a much improved representation of the organic tissue dataset than Silastic 3481 (Fig.8a, 8c). A maximal error of $149 \%$ was recorded at low strains $(<0.2)$ beyond which the PDMS simulant was within a 50\% error. Silastic 3481 showed a $4086 \%$ error in the low strain range and a response typically between $250-500 \%$ beyond this point.

The contracted muscle tissue simulant showed a greater divergence from the organic tissue dataset and generally presented a broadly comparable response to the Silastic 3481 simulant (Fig. 8b, 8d). A significant improvement, however, is apparent at low strains $(<0.1)$ where the Silastic simulant showed an $896 \%$ error compared to a $250 \%$ error in the PDMS simulant at the same strain (Fig. 8e).

At increased strain rates, the PDMS silicones continued to exhibit an improved representation of the organic tissue behaviour than the Silastic simulant (Fig. 12). The silicones, however, typically exhibited a greater stiffness than the organic tissues at higher strain rates; this response was most pronounced in the relaxed muscle simulant. A large divergence was also present in both simulants between 0.1 and 0.3 strain, where the organic tissue exhibits softer behaviour. 
Overall, the silicones exhibited an increase in maximal stress response of $12.9 \times\left(0.4-112 \mathrm{~s}^{-1}\right)$ and $8.3 \times\left(0.4-194 \mathrm{~s}^{-1}\right)$ at 0.5 strain in relaxed and contracted muscle tissues respectively. Previous skeletal muscle tissue characterisation studies have generated varied findings. Van Loocke et al. (2008) observed a $5 \times$ increase in maximal stress between $0.05 \mathrm{~s}^{-1}$ and $10 \mathrm{~s}^{-1}$, whilst Van Loocke et al. (2009) observed an increase of $4.1 \times$ from $5-3200 \mathrm{~s}^{-1}$ at 0.3 strain. Similarly, Chawla et al. (2009) observed a $1.7 \times$ increase in maximal stress between $554 \mathrm{~s}^{-1}$ and $1001 \mathrm{~s}^{-1}$ at 0.2 strain. In contrast, Van Sligtenhorst et al. (2006) observed an increase of maximal stress of approximately $17 \times$ between $0.01 \mathrm{~s}^{-1}$ and $2300 \mathrm{~s}^{-1}$ at 0.8 strain and Song et al. (2007) observed an $11 \times$ increase in maximal stress response between 0.007 and $3700 \mathrm{~s}^{-1}$ at 0.5 strain. The differences in magnitude appear to be largely indicative of the level of compressive strain applied and as such would suggest that the silicones are behaving in the correct response corridor at higher strain rates up to 0.5 strain.

In general, the silicone simulants exhibited a significantly stiffer response at low strains compared with the target organic tissues. This was a trend across all silicones (Silastic 3481 and PDMS) and is likely to indicate an innate difference in the mechanical behaviour with organic tissues, rather than issues with the quality of the formulations. However, although the primary target dataset is based on porcine and bovine sources, at low strain and high strain rates the formulated PDMS relaxed muscle simulant is convieniently a close match to Chawla (2009) and Balaraman et al. (2012) human tissue response data (Fig. 15).

Figure 15 - Intermediate strain rate PDMS relaxed muscle simulant responses compared with human muscle characterisation studies by Chawla et al. (2009) and Balaraman et al. (2012)

The viscoelastic properties of each simulants have also been compared to previous organic tissue studies using in vitro relaxed muscle tissue in the cross-fibre direction (Van Loocke et al., 2008). The normalised shear compliances for each simulant are compared in Figure 16.

Figure 16 - Normalised stress-time plots showing differences in stress relaxation between organic muscle tissue (Van Loocke et al., 2008) and the PDMS relaxed and contracted muscle simulants

Figure 16 shows that the organic muscle tissue exhibits significantly different stress relaxations when compared to the silicone elastomers with the magnitude of reduction after relaxation differing by $48.8 \%$ and $54.7 \%$ in relaxed and contracted simulants respectively. This could potentially be attributed to the in vitro nature of the organic stress relaxation experiment and the re-distribution or expulsion of fluid during a ramp and hold test. The viscoelasticity deficit in the PDMS simulants could be theoretically improved in further iterations of the formulations through improving the viscous behaviour of the isotropic PDMS. However, it may be beneficial to consider material formulations that simultaneously introduce anisotropy and viscous behaviour. 


\subsubsection{Can the same approach be used to match a better organic tissue data set?}

Given the range of stiffness made possible by altering cross-linker concentrations (Fig.4). The range of viable polymer and cross linker ratios outlined in $\$ 2.2$ can be used to further refine properties, and given the levels of agreement achieved matching two different sets of in vitro data in this study, it is evident there is potential for the PDMS silicone formulations to be manipulated to match new in vivo data to a similar level of success especially if not too dissimilar.

\subsubsection{Can the current PDMS simulants perfectly match organic tissue?}

It is not believed that it is possible with PDMS silicones in their current form to perfectly match a given non-linear set of organic tissue stress-strain data. As previously discussed silicones typically exhibited a greater stiffness at low strains followed by a reduced magnitude of strain hardening at higher strains. The silicone elastomers have also been shown to exhibit an increased stiffness at higher strain rates than organic tissues. These innate differences indicate that the PDMS silicones in their current form could not provide an exact match of a particular set of organic tissue properties.

\subsection{Applications and Further Study}

The presented PDMS silicones have demonstrated capabilities to match target organic tissue datasets and showed improvements in response when compared with previously used surrogate materials. The primary application of these materials is in human impact surrogates, where their merit is in providing an improved representation of overall human impact response. The simulants are intended for use in surrogates representing fleshy areas of the human body such as the thigh, lower leg or upper arm. These structures are also primarily developed to represent blunt trauma normal to the direction of impact and are designed to be good at approximating the net effects of soft tissues in the regions. Conversely, the surrogate structures would not be suitable for modelling injury scenarios such as penetrating impacts, oblique impacts and adverse joint kinematics.

Although the simulants have been characterised extensively, their ultimate response and relative merits remain undetermined until tested, computationally or experimentally, in a surrogate model. A key area for further development of these technologies is through fabrication of bulk synthetic models which would improve understanding of their mechanical response when subject to a wider range of mechanical loading introduced by sports specific impact conditions. Furthermore, the simulants have only been tested and compared to target organic tissue datasets in compression. The anisotropic properties of silicones and behaviour under different loading modes (e.g. predominantly tensile, shear) have not been investigated in this study and represent an area for further study. The development of such simulants could potentially enhance experimentation of different injury types not suited to isotropic materials (e.g. muscle strains, tears).

In addition, the development of skin and subcutaneous adipose tissue simulants are believed to be important in the construction of a more anatomically accurate multi-material soft tissue 
surrogate. Although, it is unclear as to whether PDMS silicones will be capable of matching the mechanical properties of very soft (adipose) or very stiff (skin) tissues, current indications from their use show that they are versatile and can be easily manipulated through changes in polymer, cross linker and filler concentrations. The composite response of these tissue simulants collectively will be important to provide an improved global biofidelity and measure of assessment of injury risk and PPE effectiveness.

\section{Conclusions}

As hypothesised in the introduction (§1.3) a multi-material human soft tissue surrogate for fleshy body segments represents a significant improvement on existing single material surrogates. An initial simplification of such an approach and an intermediary stage of complexity involve the development of soft tissue simulants considering the mechanical behaviour of organic tissues in a single direction. The presented study illustrates the potential of using bespoke blends of additive cure PDMS silicones to match the mechanical properties of relaxed and contracted muscle tissues in uniaxial compression. A subset of representative organic muscle tissue properties were selected as a target dataset from which to compare the PDMS simulants against. Uniaxial compressive tests indicated that under quasi-static loading conditions the relaxed muscle simulant provided a significantly improved response when compared with Silastic 3481. The new contracted muscle simulant showed a large improvement over Silastic 3481 at low strains, but comparable responses at increased strains.

At higher strain rates the responses of the tissues were a poorer representation of the target dataset, where the PDMS silicones typically behaved significantly stiffer than the organic tissues. Nevertheless, the PDMS silicones developed provided an improved response in comparison to the Silastic 3481 simulant. To practically understand the relative merits of the presented silicone technologies in sports specific applications, human surrogates are required. It is suggested that a multi-material surrogate embodying skin and subcutaneous adipose tissue simulants developed using these techniques potentially offers an improved overall human response and is the subject of further study.

\section{References}

ALI, A., FOULADI, M.H. and SAHARI, B., 2010. A review of constitutive models for rubber-like materials. American J.of Engineering and Applied Sciences, 3(1), pp. 232-239, DOI:10.3844/ajeassp.2010.232.239.

ARBOGAST, K.B., THIBAULT, K.L., SCOTT PINHEIRO, B., WINEY, K.I. and MARGULIES, S.S., 1997. A high-frequency shear device for testing soft biological tissues. Journal of Biomechanics, 30(7), pp. 757-759, DOI:10.1016/S0021-9290(97)00023-7.

ASTM STANDARD D1349, 2009. Standard Practice for Rubber-Standard Temperatures for Testing. West Conshohocken, PA: ASTM International.

ASTM STANDARD D395, 2008. Standard Test Methods for Rubber Property-Compression Set. West Conshohocken, PA: ASTM International,.

ASTM STANDARD D6417, Standard Test Method for Vulcanised Rubber and Thermoplastic Elastomer Determination of Force Decay (Stress Relaxation) in Compression. ASTM D6147 - 97(2008)e1. West Conshohocken, PA: ASTM International. 
BALARAMAN, K., MUKHERJEE, S., CHAWLA, A. and MALHOTRA, R., 2012. Dynamic Compressive Response of Human Passive Muscle using Split Hopkinson Pressure Bar. Indian Journal Of Biomechanics, 3(12)

BENSAMOUN, S.F., RINGLEB, S.I., LITTRELL, L., CHEN, Q., BRENNAN, M., EHMAN, R.L. and AN, K., 2006. Determination of thigh muscle stiffness using magnetic resonance elastography. Journal of Magnetic Resonance Imaging, 23(2), pp. 242-247, DOI:10.1002/jmri.20487.

BERGSTRÖM, J. and BOYCE, M., 1998. Constitutive modeling of the large strain time-dependent behavior of elastomers. Journal of the Mechanics and Physics of Solids, 46(5), pp. 931-954, DOI:10.1016/S00225096(97)00075-6.

BLACKBURN, J.T., BELL, D.R., NORCROSS, M.F., HUDSON, J.D. and KIMSEY, M.H., 2009. Sex comparison of hamstring structural and material properties. Clinical Biomechanics, 24(1), pp. 65-70, DOI:10.1016/j.clinbiomech.2008.10.001.

BÖL, M., KRUSE, R., EHRET, A.E., LEICHSENRING, K. and SIEBERT, T., 2012. Compressive properties of passive skeletal muscle-The impact of precise sample geometry on parameter identification in inverse finite element analysis. Journal of Biomechanics, 45(15), pp. 2673-2679, DOI:10.1016/j.jbiomech.2012.08.023.

BSI STANDARD BS 6183-3:2000, 2000. Protective equipment for cricketers - Part 3: Leg protectors for batsmen, wicketkeepers and fielders, and thigh, arm and chest protectors for batsmen. British Standards Institute, United Kingdom: .

BSI STANDARD BS:EN 13061:2009, 2009. Protective clothing - Shin guards for association football players Requirements and test methods. British Standards Institute, United Kingdom: .

BSI STANDARD BS:EN 13546:2002, 2002. Protective clothing - Hand, arm, chest. Abdomen, leg, foot and genital protectors for field hockey goal keepers and shin protectors for field players - Requirements and test methods. British Standards Institute, United Kingdom: .

CASSAGNAU, P. and MÉLIS, F., 2003. Non-linear viscoelastic behaviour and modulus recovery in silica filled polymers. Polymer, 44(21), pp. 6607-6615, DOI:10.1016/S0032-3861(03)00689-X.

CHAWLA, A., MUKHERJEE, S. and KARTHIKEYAN, B., 2009. Characterization of human passive muscles for impact loads using genetic algorithm and inverse finite element methods. Biomechanics and modeling in mechanobiology, 8(1), pp. 67-76, DOI:10.1007/s10237-008-0121-6.

CLAVERT, P., KEMPF, J., BONNOMET, F., BOUTEMY, P., MARCELIN, L. and KAHN, J.L., 2001. Effects of freezing/thawing on the biomechanical properties of human tendons. Surgical and Radiologic Anatomy, 23(4), pp. 259-262, DOI:10.1007/s00276-001-0259-8.

COSGROVE, T., TURNER, M.J. and THOMAS, D.R., 1997. The adsorption of polydimethylsiloxane onto silica from the melt. Polymer, 38(15), pp. 3885-3892, DOI:10.1016/S0032-3861(96)00955-X.

CRISCO, J., HENTEL, K., JACKSON, W., GOEHNER, K. and JOKL, P., 1996. Maximal contraction lessens impact response in a muscle contusion model. Journal of Biomechanics, 29(10), pp. 1291-1296, DOI:10.1016/0021-9290(96)00047-4.

DIANI, J., FAYOLLE, B. and GILORMINI, P., 2009. A review on the Mullins effect. European Polymer Journal, 45(3), pp. 601-612, DOI:10.1016/j.eurpolymj.2008.11.017.

DORFMANN, A. and OGDEN, R., 2004. A constitutive model for the Mullins effect with permanent set in particle-reinforced rubber. International Journal of Solids and Structures, 41(7), pp. 1855-1878, DOI:10.1016/j.ijsolstr.2003.11.014.

DOUGLAS, W.R., 1972. Of pigs and men and research: a review of applications and analogies of the pig, sus scrofa, in human medical research. Space life sciences, 3(3), pp. 226-234, DOI:10.1007/BF00928167.

FUNG, Y., 1993. Biomechanics: mechanical properties of living tissues. 2nd ed. edn. The University of Michigan, USA: Springer.

GELEST, 2014. Reactive Silicones: Forging New Polymer Links. Morrisville, PA, USA: Gelest Inc.

GRAY III, G.T., BLUMENTHAL, W.R., TRUJILLO, C. and CARPENTER, R.W., 1997. Influence of temperature and strain rate on the mechanical behavior of adiprene L-100. Le Journal de Physique IV, 7(C3), pp. 523-528, DOI:10.1051/jp4:1997390. 
HOFFER, J. and ANDREASSEN, S., 1981. Regulation of soleus muscle stiffness in premammillary cats: intrinsic and reflex components. Journal of neurophysiology, 45(2), pp. 267-285.

HRYSOMALLIS, C., 2009. Surrogate thigh model for assessing impact force attenuation of protective pads. Journal of Science and Medicine in Sport, 12(1), pp. 35-41, DOI:10.1016/j.jsams.2007.07.013.

ISO STANDARD 3384-1:2011, 2011. Rubber, vulcanized or thermoplastic — Determination of stress relaxation in compression - Part 1: Testing at constant temperature. Geneva, Switzerland: International Organization for Standardization.

JONES, J., 1960. Tensile testing of elastomers at ultra-high strain rates. Journal of Applied Polymer Science, 4(12), pp. 284-290, DOI:10.1002/app.1960.070041206.

KAKAVAS, P.A., 1996. Mechanical properties of bonded elastomer discs subjected to triaxial stress. Journal of Applied Polymer Science, 59(2), pp. 251-261, DOI:10.1002/(SICI)1097-4628(19960110)59:2<251::AIDAPP9>3.0.CO;2-W.

LEE, K.E. and PELKER, R.R., 1985. Effect of freezing on histologic and biomechanical failure patterns in the rabbit capital femoral growth plate. J Orthop Res, 3(3), pp. 514-515, DOI:10.1002/jor.1100030415.

LEE, O.S., KIM, M.S., KIM, K.J., HWANG, S.W. and CHO, K.S., 2003. Dynamic deformation behavior of rubber under high strain rate compressive loading. International Journal of Modern Physics B, 17(08n09), pp. 1415-1420, DOI:10.1142/S0217979203019083.

MARCKMANN, G. and VERRON, E., 2006. Comparison of hyperelastic models for rubber-like materials. Rubber chemistry and technology, 79(5), pp. 835-858, DOI:10.5254/1.3547969.

MARTINEZ, J.S., LE CAM, J., BALANDRAUD, X., TOUSSAINT, E. and CAILLARD, J., 2013. Filler effects on the thermomechanical response of stretched rubbers. Polymer Testing, 32(5), pp. 835-841, DOI:10.1016/j.polymertesting.2013.04.003.

MCELHANEY, J.H., 1966. Dynamic response of bone and muscle tissue. Journal of applied physiology, 21(4), pp. 1231-1236.

MENZ, L.J., 1971. Structural changes and impairment of function associated with freezing and thawing in muscle, nerve, and leucocytes. Cryobiology, 8(1), pp. 1-131.

MEUNIER, L., CHAGNON, G., FAVIER, D., ORGÉAS, L. and VACHER, P., 2008. Mechanical experimental characterisation and numerical modelling of an unfilled silicone rubber. Polymer Testing, 27(6), pp. 765-777, DOI:10.1016/j.polymertesting.2008.05.011.

MOTTAHEDI, M., DADALAU, A., HAFLA, A. and VERL, A., 2011. Numerical Analysis of Relaxation Test Based on Prony Series Material Model. In: M. FATHI, A. HOLLAND, F. ANSARI and C. WEBER, eds, Integrated Systems, Design and Technology 2010. Berlin Heidelberg: Springer, pp. 79-91.

MULLINS, L. and TOBIN, N., 1965. Stress softening in rubber vulcanizates. Part I. Use of a strain amplification factor to describe the elastic behavior of filler-reinforced vulcanized rubber. Journal of Applied Polymer Science, 9(9), pp. 2993-3009, DOI:10.1002/app.1965.070090906.

MULLINS, L., 1969. Softening of rubber by deformation. Rubber Chemistry and Technology, 42(1), pp. 339362, DOI:10.5254/1.3539210.

OGDEN, R., 1972. Large deformation isotropic elasticity-on the correlation of theory and experiment for incompressible rubberlike solids. Proceedings of the Royal Society of London.A.Mathematical and Physical Sciences, 326(1567), pp. 565-584, DOI:10.1098/rspa.1972.0026.

PAYNE, T., MITCHELL, S.R., BIBB, R. and WATERS, M., 2014. Initial Validation of a Relaxed Human Soft Tissue Simulant for Sports Impact Surrogates. Procedia Engineering, 72, pp. 533-538, DOI:10.1016/j.proeng.2014.06.092.

PENROSE, T., FOSTER, D. and BLANKSBY, B., 1976. Release velocities of fast bowlers during a cricket test match. Australian Journal for Health, Physical Education and Recreation, 71(Supplement to Australian Journal for Health, Physical Recreation \& Education), pp. 2-5.

PODNOS, E., BECKER, E., KLAWITTER, J. and STRZEPA, P., 2006. FEA analysis of silicone MCP implant. Journal of Biomechanics, 39(7), pp. 1217-1226, DOI:10.1016/j.jbiomech.2005.03.019. 
RAULT, J., MARCHAL, J., JUDEINSTEIN, P. and ALBOUY, P., 2006. Stress-induced crystallization and reinforcement in filled natural rubbers: 2H NMR study. Macromolecules, 39(24), pp. 8356-8368, DOI:10.1021/ma0608424.

REY, T., CHAGNON, G., LE CAM, J. and FAVIER, D., 2013. Influence of the temperature on the mechanical behaviour of filled and unfilled silicone rubbers. Polymer Testing, 32(3), pp. 492-501, DOI:10.1016/j.polymertesting.2013.01.008.

RIVLIN, R., 1948. Large elastic deformations of isotropic materials. II. Some uniqueness theorems for pure, homogeneous deformation. Philosophical Transactions of the Royal Society of London. Series A, Mathematical and Physical Sciences, 240(822), pp. 491-508, DOI:10.1098/rsta.1948.0003.

SALEM, R.O., LAPOSATA, M., RAJENDRAM, R., CLUETTE-BROWN, J.E. and PREEDY, V.R., 2006. The total body mass of fatty acid ethyl esters in skeletal muscles following ethanol exposure greatly exceeds that found in the liver and the heart. Alcohol and Alcoholism (Oxford, Oxfordshire), 41(6), pp. 598-603, DOI:10.1093/alcalc/agl069.

SARAF, H., RAMESH, K., LENNON, A., MERKLE, A. and ROBERTS, J., 2007. Mechanical properties of soft human tissues under dynamic loading. Journal of Biomechanics, 40(9), pp. 1960-1967, DOI:10.1016/j.jbiomech.2006.09.021.

SHERGOLD, O.A., FLECK, N.A. and RADFORD, D., 2006. The uniaxial stress versus strain response of pig skin and silicone rubber at low and high strain rates. International Journal of Impact Engineering, 32(9), pp. 1384-1402, DOI:10.1016/j.ijimpeng.2004.11.010.

SNEDEKER, J., BARBEZAT, M., NIEDERER, P., SCHMIDLIN, F. and FARSHAD, M., 2005. Strain energy density as a rupture criterion for the kidney: impact tests on porcine organs, finite element simulation, and a baseline comparison between human and porcine tissues. Journal of Biomechanics, 38(5), pp. 993-1001, DOI:10.1016/j.jbiomech.2004.05.030.

SONG, B., CHEN, W., GE, Y. and WEERASOORIYA, T., 2007. Dynamic and quasi-static compressive response of porcine muscle. Journal of Biomechanics, 40(13), pp. 2999-3005, DOI:10.1016/j.jbiomech.2007.02.001.

TRELOAR, L., 1943. The elasticity of a network of long-chain molecules-II. Transactions of the Faraday Society, 39, pp. 241-246, DOI:10.1039/tf9433900241.

TREXLER, M., LENNON, A., WICKWIRE, A., HARRIGAN, T., LUONG, Q., GRAHAM, J., MAISANO, A., ROBERTS, J. and MERKLE, A., 2011. Verification and implementation of a modified split Hopkinson pressure bar technique for characterizing biological tissue and soft biosimulant materials under dynamic shear loading. Journal of the mechanical behavior of biomedical materials, 4(8), pp. 1920-1928, DOI:10.1016/j.jmbbm.2011.06.008.

TSCHOEGL, N.W., 1989. The Phenomenological Theory of Linear Viscoelastic Behavior: An Introduction. New York: Springer.

TSUI, F. and PAIN, M., 2008. The effects of muscle tension on human biomechanical response and perceived impact intensity, Proceedings of the 4th North American Congress on Biomechanics, Ann Arbor, USA, August 2008 2008, pp. 222-236.

VAN EE, C., CHASSE, A. and MYERS, B., 2000. Quantifying skeletal muscle properties in cadaveric test specimens: effects of mechanical loading, postmortem time, and freezer storage. Journal of Biomechanical Engineering, 122(1), pp. 9-14, DOI:10.1115/1.429621.

VAN LOOCKE, M., LYONS, C. and SIMMS, C., 2006. A validated model of passive muscle in compression. Journal of Biomechanics, 39(16), pp. 2999-3009, DOI:10.1016/j.jbiomech.2005.10.016.

VAN LOOCKE, M., LYONS, C. and SIMMS, C., 2008. Viscoelastic properties of passive skeletal muscle in compression: stress-relaxation behaviour and constitutive modelling. Journal of Biomechanics, 41(7), pp. 15551566, DOI:10.1016/j.jbiomech.2008.02.007.

VAN LOOCKE, M., SIMMS, C. and LYONS, C., 2009. Viscoelastic properties of passive skeletal muscle in compression-Cyclic behaviour. Journal of Biomechanics, 42(8), pp. 1038-1048,

DOI:10.1016/j.jbiomech.2009.02.022. 
VAN SLIGTENHORST, C., CRONIN, D.S. and WAYNE BRODLAND, G., 2006. High strain rate compressive properties of bovine muscle tissue determined using a split Hopkinson bar apparatus. Journal of Biomechanics, 39(10), pp. 1852-1858, DOI:10.1016/j.jbiomech.2005.05.015.

WANG, C., ZHENG, Y., XIAO, Y., QIU, W. and ZHENG, H., 2012. Using vibro-ultrasound method to assess the vastus intermedius stiffness over the entire range of step isometric contraction of knee extensors, Ultrasonics Symposium (IUS), 2012 IEEE International, 7th-10th October 2012 2012, IEEE, pp. 1351135410.1109/ULTSYM.2012.0337.

WANG, Z., DEURENBERG, P., WANG, W. and HEYMSFIELD, S., 1997. Proportion of adipose tissue-free body mass as skeletal muscle: Magnitude and constancy in men. American Journal of Human Biology, 9(4), pp. 487-492, DOI:0.1002/(SICI)1520-6300(1997)9:4<487::AID-AJHB8>3.0.CO;2-T.

WU, J.Z., DONG, R.G. and SCHOPPER, A.W., 2004. Analysis of effects of friction on the deformation behavior of soft tissues in unconfined compression tests. Journal of Biomechanics, 37(1), pp. 147-155, DOI:10.1016/S0021-9290(03)00240-9.

YAMADA, H., 1970. Strength of biological materials. Baltimore, Maryland, USA: Williams \& Wilkins.

YAN, L., DILLARD, D.A., WEST, R.L., RUBIS, K.J. and GORDON, G.V., 2012. Strain rate and temperature dependence of a nanoparticle-filled poly (dimethylsiloxane) undergoing shear deformation. Journal of Polymer Science Part B: Polymer Physics, 50(13), pp. 929-937, DOI:10.1002/polb.23088.

ZHENG, Y., MAK, A.F. and LUE, B., 1999. Objective assessment of limb tissue elasticity: development of a manual indentation procedure. Journal of rehabilitation research and development, 36(2), pp. 71-85. 
Figures \& Tables

\begin{tabular}{|c|c|c|c|c|c|c|c|}
\hline & \multicolumn{4}{|c|}{ Part A } & \multicolumn{2}{|c|}{ Part B } & \multirow{3}{*}{$\begin{array}{c}\text { Part A:B } \\
\text { Ratio }\end{array}$} \\
\hline & \multicolumn{3}{|c|}{ Polymers } & \multirow{2}{*}{ Catalyst } & \multirow{2}{*}{$\begin{array}{l}\text { H301 Cross } \\
\text { Linker }\end{array}$} & \multirow{2}{*}{$\begin{array}{c}\text { V31 } \\
\text { Polymer }\end{array}$} & \\
\hline & V46 & V31 & V21 & & & & \\
\hline Relaxed Muscle & $46.8 \%$ & $28.8 \%$ & $14.4 \%$ & \multirow{2}{*}{$10 \%$} & \multirow{2}{*}{$10 \%$} & \multirow{2}{*}{$90 \%$} & $4: 1$ \\
\hline Contracted Muscle & $46.8 \%$ & $21.6 \%$ & $21.6 \%$ & & & & $3: 1$ \\
\hline
\end{tabular}

Table 6 - Part A and B silicone constituent concentrations (\% by mass)

\begin{tabular}{ccccc}
\hline & & $\boldsymbol{C}_{\boldsymbol{1}}$ & $\boldsymbol{C}_{\mathbf{0 1}}$ & $\boldsymbol{R M S}$ Error (MPa) \\
\hline \multirow{3}{*}{ Relaxed Muscle } & $0.4 \mathrm{~s}^{-1}$ & $-4.07 \times 10^{3}$ & $8.29 \times 10^{3}$ & 0.293 \\
& $70 \mathrm{~s}-1$ & $-4.00 \times 10^{-3}$ & $1.57 \times 10^{4}$ & 0.0368 \\
& $112 \mathrm{~s}-1$ & $2.24 \times 10^{5}$ & $-3.49 \times 10^{4}$ & 0.0890 \\
\hline \multirow{2}{*}{ Contracted Muscle } & $0.4 \mathrm{~s}^{-1}$ & $6.00 \times 10^{4}$ & $-1.12 \times 10^{3}$ & 0.00769 \\
& $50 \mathrm{~s}^{-1}$ & $-7.76 \times 10^{4}$ & $1.23 \times 10^{5}$ & 0.0203 \\
& $194 \mathrm{~s}^{-1}$ & $-1.70 \times 10^{5}$ & $3.03 \times 10^{5}$ & 0.229 \\
\hline
\end{tabular}

Table 7 - Mooney-Rivlin model coefficients for PDMS simulants

\begin{tabular}{ccccc}
\hline & & $\boldsymbol{\mu}$ & $\boldsymbol{\alpha}$ & $\boldsymbol{R M S}$ Error (MPa) \\
\hline \multirow{2}{*}{$\begin{array}{c}\text { Relaxed } \\
\text { Muscle }\end{array}$} & $0.4 \mathrm{~s}^{-1}$ & $1.72 \times 10^{4}$ & 5.14 & 0.0232 \\
& $70 \mathrm{~s}-1$ & $2.51 \times 10^{4}$ & 7.36 & 0.00715 \\
& $112 \mathrm{~s}^{-1}$ & $3.29 \times 10^{5}$ & 1.50 & 0.00942 \\
\hline \multirow{2}{*}{$\begin{array}{c}\text { Contracted } \\
\text { Muscle }\end{array}$} & $0.4 \mathrm{~s}^{-1}$ & $1.16 \times 10^{5}$ & 1.73 & 0.00799 \\
& $50 \mathrm{~s}^{-1}$ & $1.66 \times 10^{5}$ & 7.40 & 0.0658 \\
\hline
\end{tabular}

Table 8 - Ogden model coefficients for PDMS Simulants

\begin{tabular}{cccc}
\hline & & $\boldsymbol{C}_{10}$ & $\boldsymbol{R M S}$ Error $(\mathbf{M P a})$ \\
\hline \multirow{2}{*}{$\begin{array}{c}\text { Relaxed } \\
\text { Muscle }\end{array}$} & $0.4 \mathrm{~s}^{-1}$ & $1.38 \times 10^{4}$ & 0.0843 \\
& $70 \mathrm{~s}-1$ & $1.34 \times 10^{4}$ & 0.0931 \\
& $112 \mathrm{~s}^{-1}$ & $1.67 \times 10^{5}$ & 0.0995 \\
\hline \multirow{2}{*}{$\begin{array}{c}\text { Contracted } \\
\text { Muscle }\end{array}$} & $0.4 \mathrm{~s}^{-1}$ & $5.81 \times 10^{4}$ & 0.0119 \\
& $50 \mathrm{~s}^{-1}$ & $8.92 \times 10^{4}$ & 0.176 \\
\hline
\end{tabular}

Table 9 - Neo Hooke model coefficients for PDMS simulants

\begin{tabular}{cccc}
\hline & $\boldsymbol{i}$ & $\boldsymbol{g ( i )}$ & $\boldsymbol{\tau}(\mathbf{i})$ \\
\hline & 1 & $1.28 \times 10^{-1}$ & $3.52 \times 10^{-1}$ \\
Relaxed Muscle & 2 & $5.29 \times 10^{-2}$ & 8.07 \\
& 3 & $3.39 \times 10^{-2}$ & $7.61 \times 10^{1}$ \\
\hline & 1 & $4.83 \times 10^{-2}$ & $3.25 \times 10^{-1}$ \\
Contracted Muscle & 2 & $3.66 \times 10^{-2}$ & 6.91 \\
& 3 & $2.70 \times 10^{-2}$ & $8.49 \times 10^{1}$ \\
\hline
\end{tabular}

Table 10 - Prony series coefficients for PDMS simulants

Page $\mathbf{2 6}$ of $\mathbf{3 3}$ 


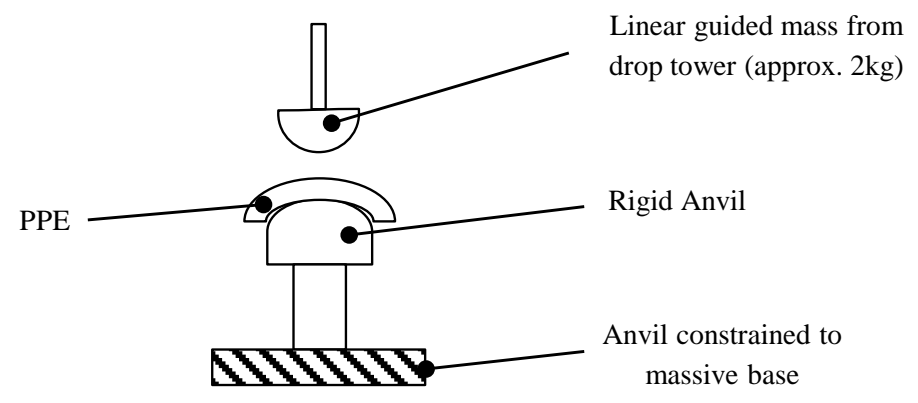

Figure 1 - Schematic showing a typical sports safety standard protocol used to assess projectile impacts (BS:13546:2002 Field Hockey Goalkeeper Protective Clothing; BS:6183-3:2000 Cricket Leg Protectors)

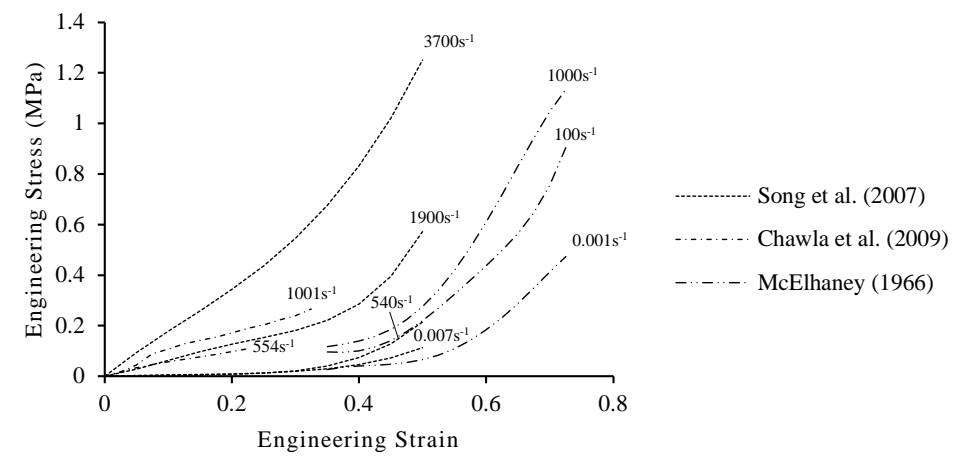

Figure 17 - Compressive engineering stress-strain plot showing data from previous organic tissue characterisation studies
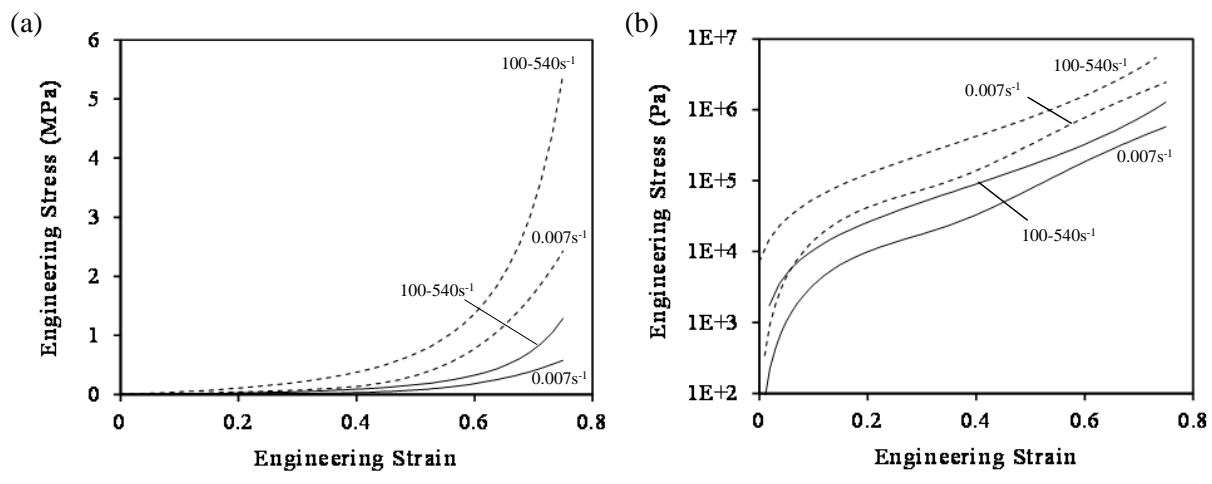

- Relaxed Muscle

Contracted Muscle

Figure 18 - Engineering stress-strain graphs showing organic tissue properties from relaxed (McElhaney, 1966; Song et al., 2007) and contracted (Zheng et al., 1999) muscle tissue in (a) linear and (b) log-linear plots 
(a)

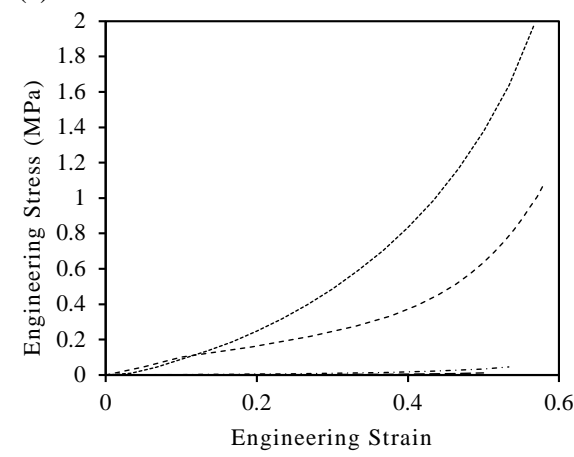

(b)

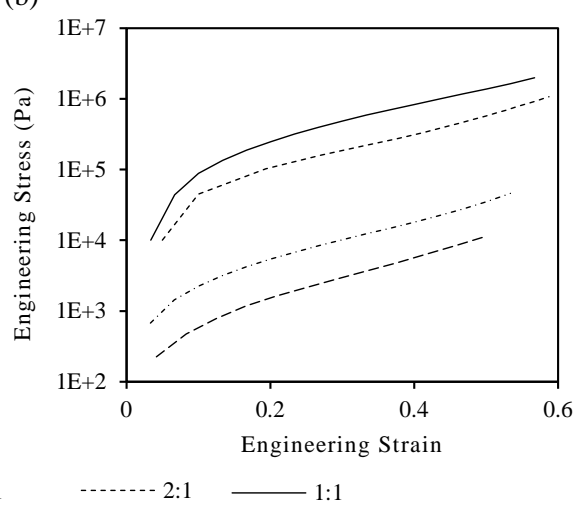

Figure 19 - Quasi-static compressive engineering stress-strain plot of silicones with different cross-linker concentrations in: (a) linear and (b) log-linear graphs

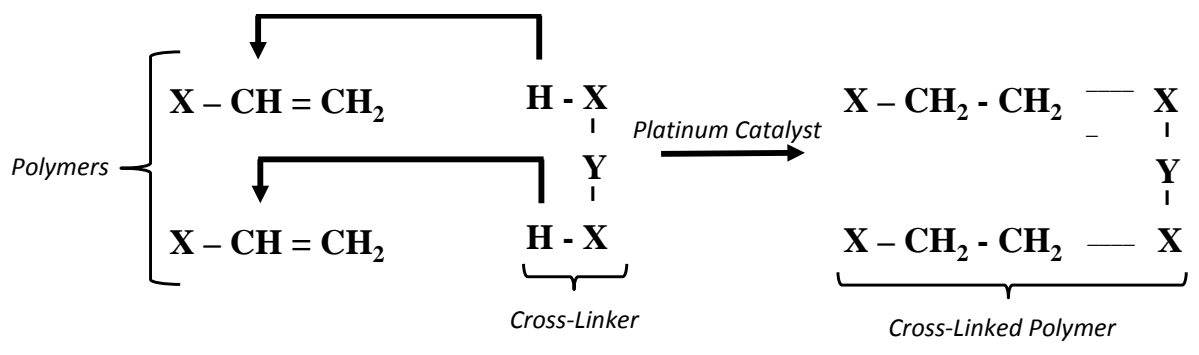

Figure 20 - Chemical structure of additive cure PDMS silicone reaction

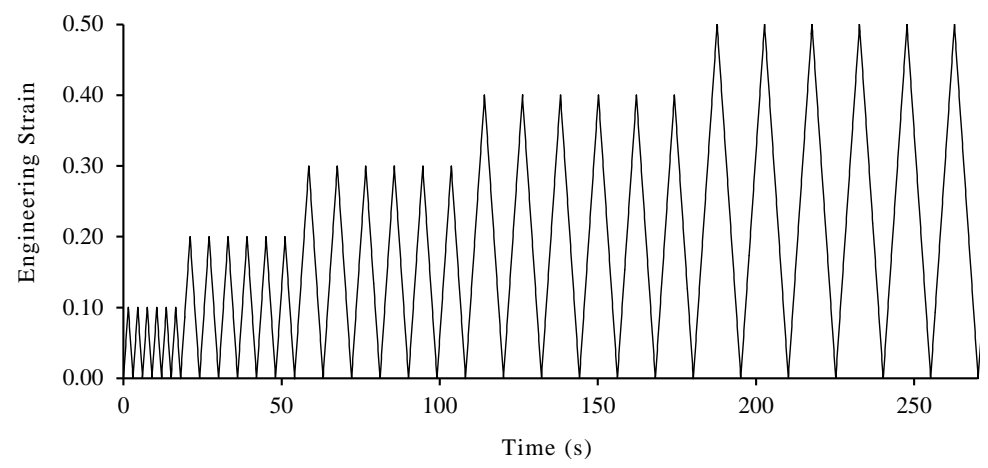

Figure 21 - Programmed triangular loading profile for quasi-static uniaxial compressive tests 

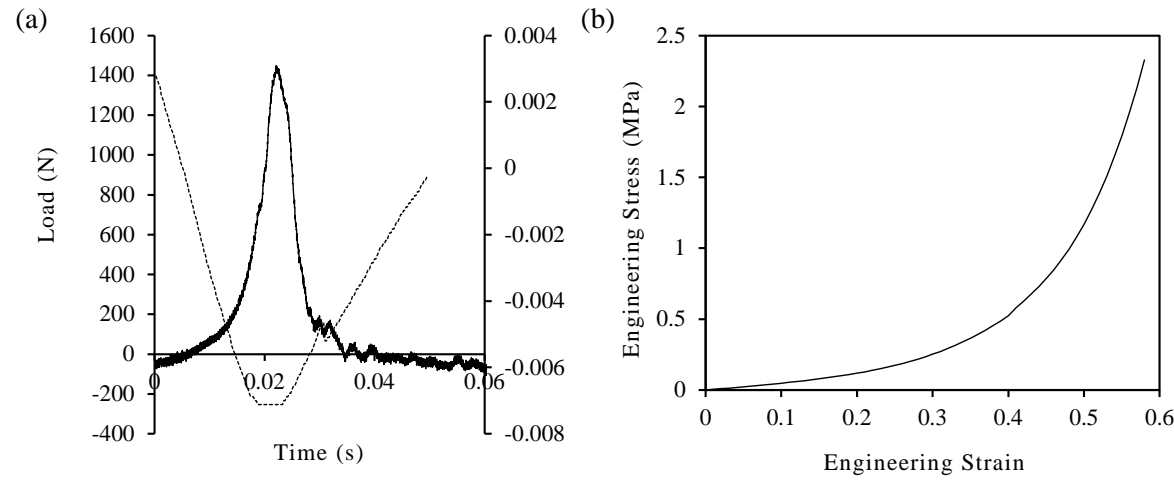

Figure 22 - Processing of intermediate strain rate drop tower data: (a) raw data; (b) smoothed stress-strain plot 
(a)

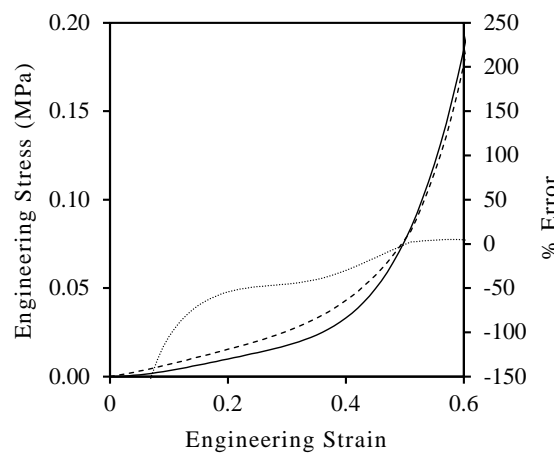

(c)

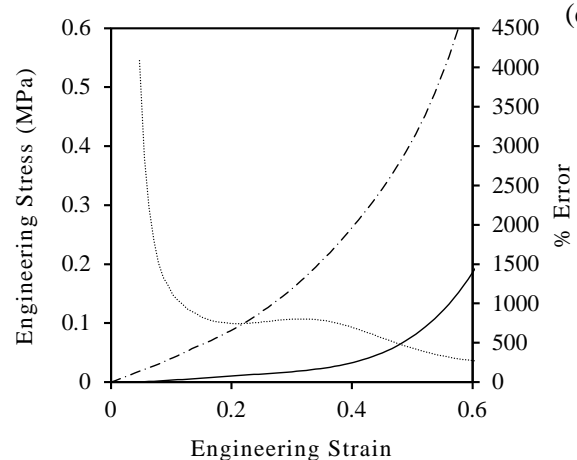

(b)

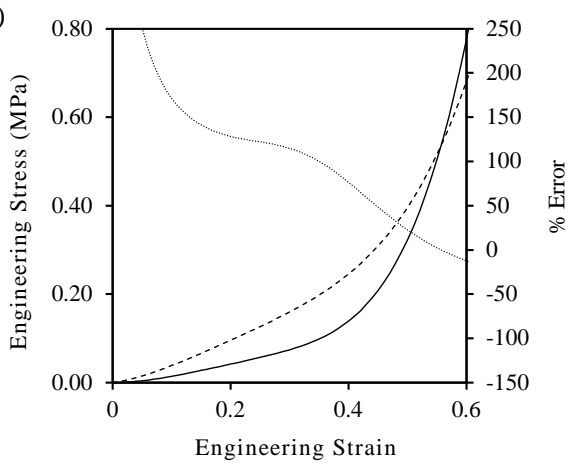

(d)

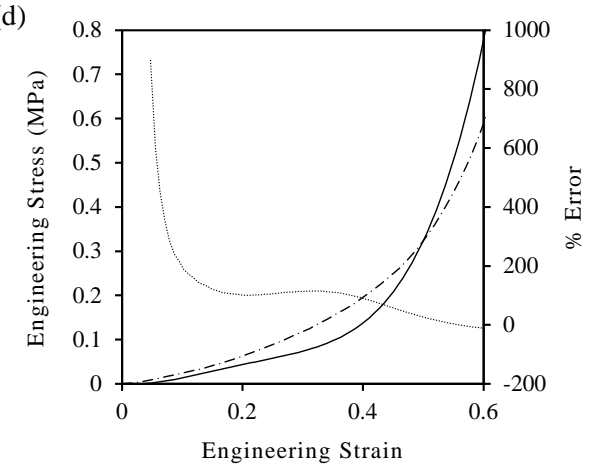

(e)

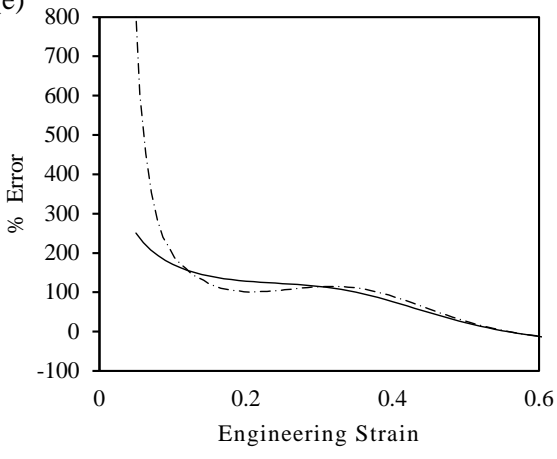

Figure 23 - Quasi-static stress-strain plots showing the divergences in compressive response between: (a) PDMS relaxed muscle simulant and organic tissue data; (b) PDMS contracted muscle simulant with organic tissue data; (c) Silastic 3481 with relaxed organic tissue data; (d) Silastic 3481 with contracted muscle organic tissue data; (e) Percentage errors plots showing divergence between silicone simulants and target organic contracted muscle data 
(a)

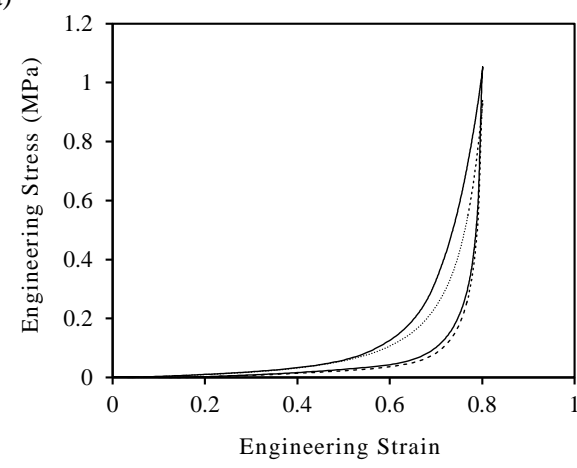

(b)

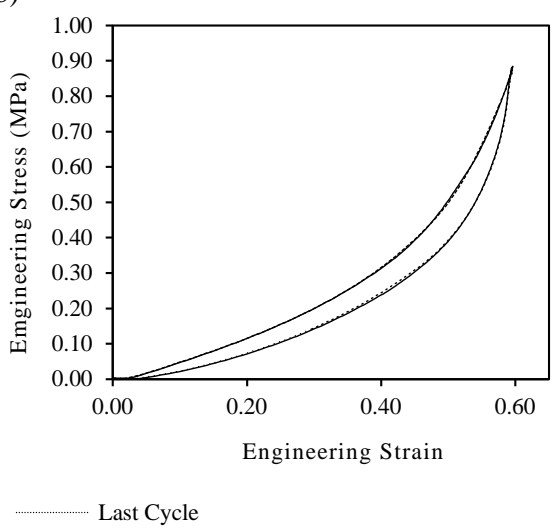

Figure 24 - Engineering stress-strain plot showing stress softening effect in cyclic compressive protocol between the first and last cycles in: (a) PDMS relaxed muscle simulant and (b) PDMS contracted muscle simulant

(a)

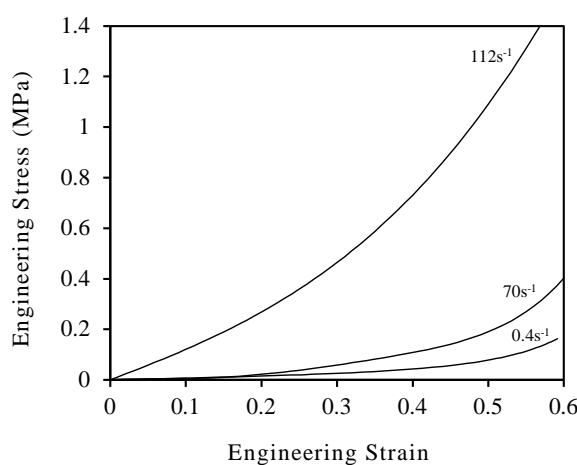

(b)

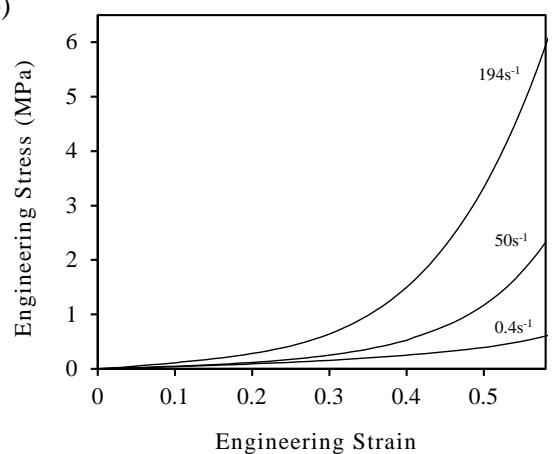

Figure 25 - Intermediate strain rate engineering stress-strain curves for: (a) PDMS relaxed muscle simulant and (b) PDMS contracted muscle simulant

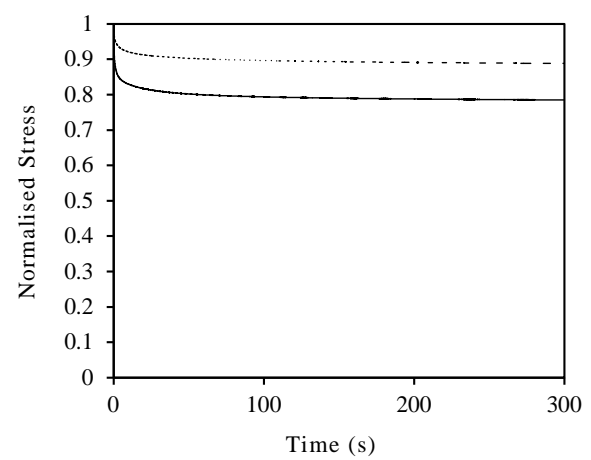

_ Relaxed Muscle Simulant _...-..-... Contracted Muscle Simulant

Figure 26 Normalised stress-time plot showing stress relaxation in PDMS relaxed and contracted muscle simulants

Page 31 of 33 
(a)

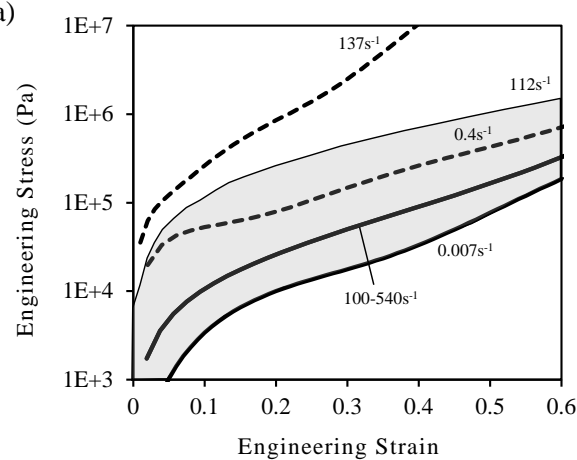

(b)

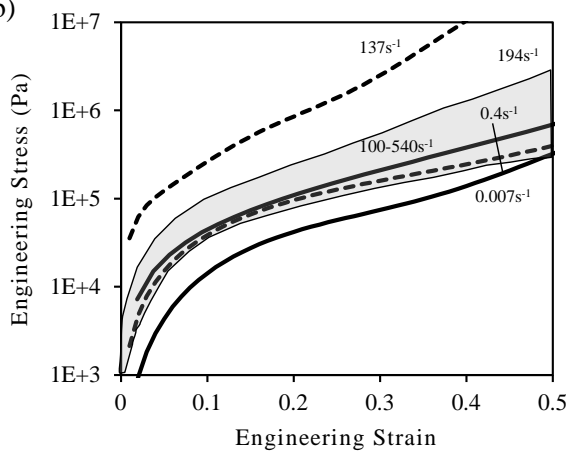

— Organic Tissue $\left(0.007 \mathrm{~s}^{-1} ; 100-540 \mathrm{~s}^{-1}\right) \quad$ - - - - Silastic $3481\left(0.4-137 \mathrm{~s}^{-1}\right)$

PDMS Simulant (Relaxed Muscle: 0.4-112 $\mathrm{s}^{-1}$; Contracted Muscle: $0.4-194 \mathrm{~s}^{-1}$ )

Figure 27 - Log-linear engineering stress-strain plots showing a comparison between Silastic 3481, PDMS silicones and organic tissue properties for: (a) PDMS relaxed muscle simulant and (b) PDMS contracted muscle simulant

(a)

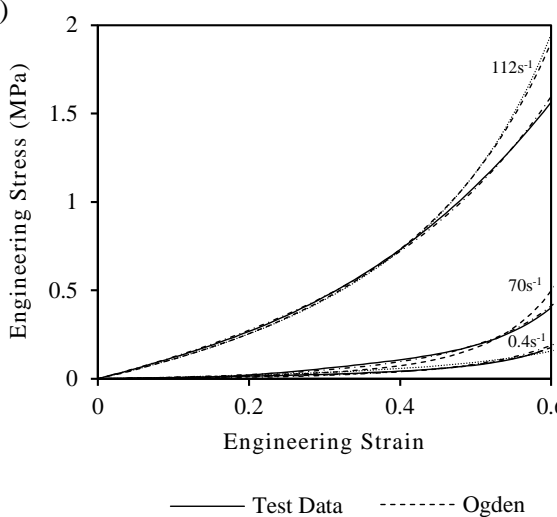

(b)

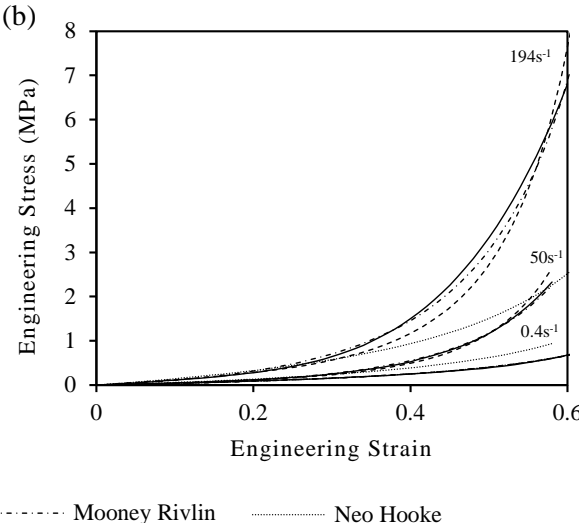

Figure 28 - Hyperelastic model fits for: (a) PDMS relaxed muscle simulant and (b) PDMS contracted muscle simulant at a range of intermediate strain rates 
(a)

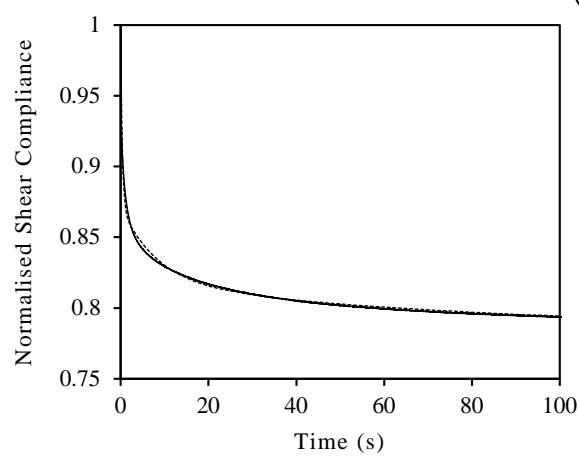

Silicone Simulants (b)

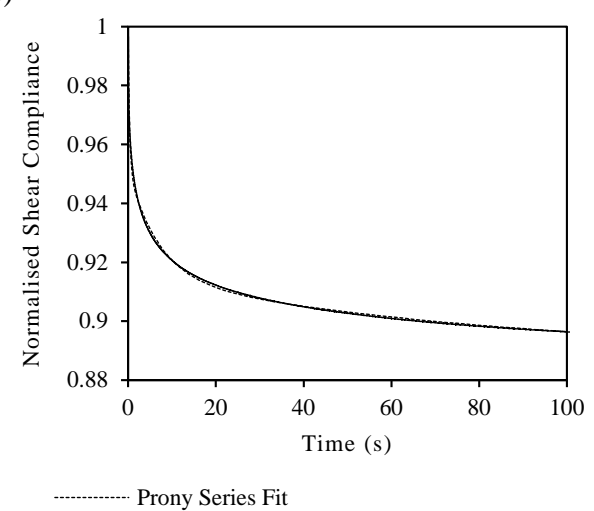

Figure 29 - Prony series model fits for: (a) PDMS relaxed muscle simulant and (b) PDMS contracted muscle simulants

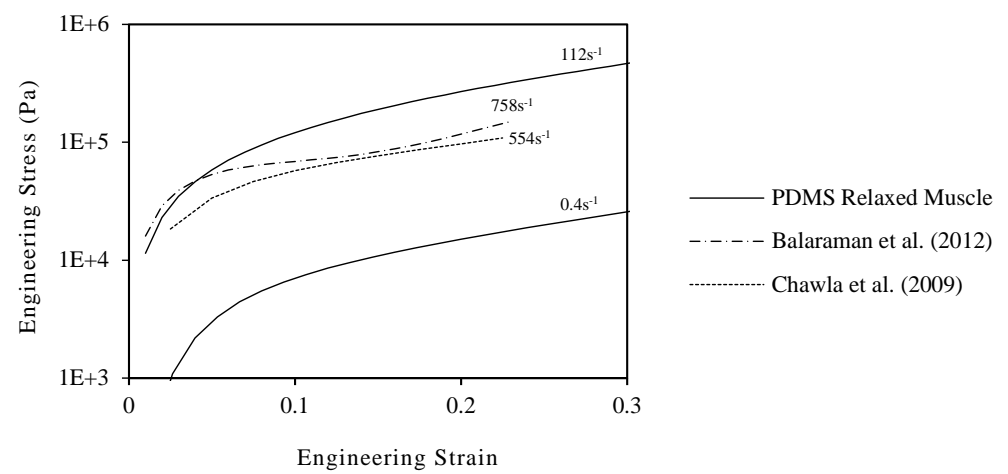

Figure 30 - Intermediate strain rate PDMS relaxed muscle simulant responses compared with human muscle characterisation studies by Chawla et al. (2009) and Balaraman et al. (2012)

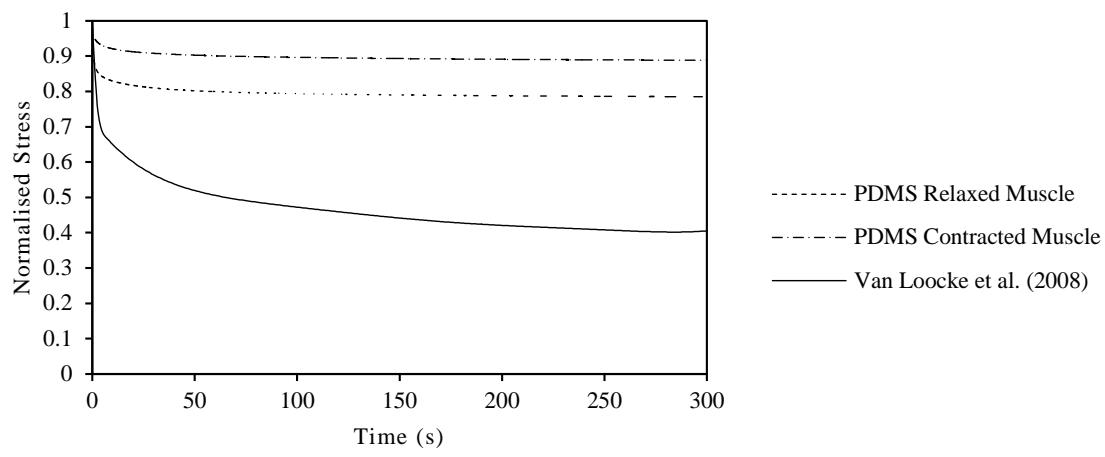

Figure 31 - Normalised stress-time plots showing differences in stress relaxation between organic muscle tissue (Van Loocke et al., 2008) and the PDMS relaxed and contracted muscle simulants 